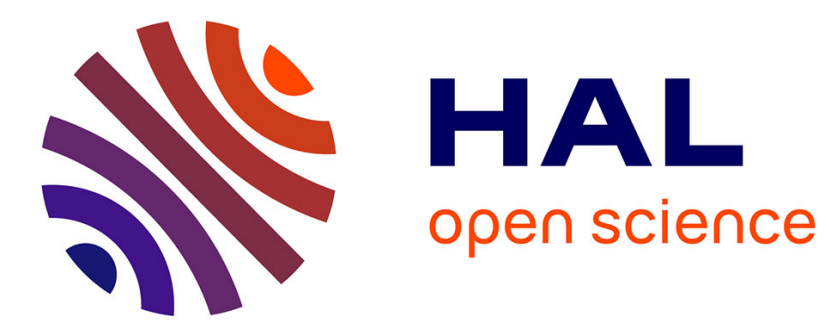

\title{
Experimental study on drilling mechanisms and strategies of hybrid CFRP/Ti stacks
}

\author{
Jinyang Xu, Mohamed El Mansori
}

\section{To cite this version:}

Jinyang $\mathrm{Xu}$, Mohamed El Mansori. Experimental study on drilling mechanisms and strategies of hybrid CFRP/Ti stacks. Composite Structures, 2016, 157, pp.461-482. 10.1016/j.compstruct.2016.07.025 . hal-02417629

\section{HAL Id: hal-02417629 \\ https://hal.science/hal-02417629}

Submitted on 18 Dec 2019

HAL is a multi-disciplinary open access archive for the deposit and dissemination of scientific research documents, whether they are published or not. The documents may come from teaching and research institutions in France or abroad, or from public or private research centers.
L'archive ouverte pluridisciplinaire HAL, est destinée au dépôt et à la diffusion de documents scientifiques de niveau recherche, publiés ou non, émanant des établissements d'enseignement et de recherche français ou étrangers, des laboratoires publics ou privés. 


\title{
Experimental study on drilling mechanisms and strategies of hybrid CFRP/Ti stacks
}

\author{
Jinyang $\mathrm{Xu}^{\mathrm{a}, \mathrm{b}, *}$, Mohamed El Mansori ${ }^{\mathrm{a}}$ \\ ${ }^{a}$ MSMP - EA 7350, Arts et Métiers ParisTech, Rue Saint Dominique, BP 508, Châlons-en-Champagne 51006, France \\ ${ }^{\mathrm{b}}$ School of Mechanical Engineering, Shanghai Jiao Tong University, Shanghai 200240, PR China
}

Keywords:

Hybrid CFRP/Ti stack

Drilling

Cutting sequence strategy

Drill geometrical feature

Hole quality

Tool performance

\begin{abstract}
A B S T R A C T
Mechanical drilling has been frequently used for hole making of hybrid CFRP/Ti stacks in order to ensure excellent fastening assembly. Owing to their inhomogeneous behavior and poor machinability, drilling CFRP/Ti stacks in one-shot time has brought great challenges to the modern manufacturing community. Compared to the previous studies on drilling CFRP/Ti, this paper aims to highlight the following aspects: (i) the features of tool-work interaction and machinability classification in the bi-material drilling, (ii) the influences of different cutting sequences on CFRP/Ti drilling responses, and (iii) the effects of different tool geometries/materials on CFRP/Ti drilling performance. The experimental results have shown that the drill geometrical features, which ensure the cutting contacts of the stack combination, have a more significant effect on CFRP/Ti drilling output than tool material composition. The Ti $\rightarrow$ CFRP drilling strategy promotes higher quality of the machined hole surfaces (e.g., more consistent hole diameters and much better surface finish) with lower Ti burr extents, while the CFRP $\rightarrow$ Ti drilling strategy reduces only the induced delamination. The experiments discussed in this paper allow besides several recommendations for the cutting sequence selection and drill geometrical design when drilling hybrid CFRP/Ti stacks.
\end{abstract}

\section{Introduction}

Hybrid CFRP/Ti stack is an advanced composite structure that has been widely used in modern aerospace industry due to its superior mechanical/physical properties and excellent structural functions including high strength-to-weight ratio, good corrosion/erosion resistance, high design flexibility, etc. The bimaterial assembly which consists of two disparate constituents, $i$. e., carbon fiber reinforced polymer (CFRP) and Ti alloy, can provide combined structural advantages of each stacked phase while their individual weaknesses are significantly avoided [1]. For example, the Ti alloy has good strength-to-weight ratio, high fracture resistance, isotropic behavior, and exhibits good reparability [2-4], while the CFRP composite shows high specific stiffness, superior corrosion resistance, and excellent fatigue strength $[5,6]$. The combination of the metal-to-composite alliance in a hybrid composite structure typically overcomes the lack of fatigue strength and corrosion resistance of metals, and avoids the shortcoming of low

* Corresponding author at: MSMP - EA 7350, Arts et Métiers ParisTech, Rue Saint Dominique, BP 508, Châlons-en-Champagne 51006, France. Tel.: +33 03266991 67; fax: +330326 699197.

E-mail addresses: jinyang.xu@ensam.eu, jinyang.xu@hotmail.com (J. Xu). bearing/impact strength and reparable problem of composites $[7,8]$.

The emergence of such hybrid composite stack has greatly revolutionized the conventional material distribution in modern commercial aircraft. Owing to its inherent advantages, the hybrid CFRP/ Ti stack has gradually substituted conventional standard CFRP applications and single Ti alloy applications in various aerospace fields. Currently, many giant aircraft manufacturers including Airbus and Boeing are widely employing this multi-phase material in new generation commercial aircraft to produce competitive structural components (e.g., fuselages, skin segments and wing connections) that favor energy saving and benefit system performance improvement. More noteworthy, such an increasing trend is still expected to grow in the next one or two decades.

To satisfy the industrial applications, millions of holes are needed to be drilled out in the stacked materials for assembly purpose $[9,10]$. However, this bi-material system is problematic for drilling operations and is often classified as a difficult-to-cut material as reported by Xu et al. [1] in their review work on drilling of hybrid composite stacks. The key causes can be attributed to the disparate properties of the stacked constituents and their respectively poor machinability. During drilling, the problems of severe hole damage including the irreparable delamination in the 


\section{Nomenclature}

$\begin{array}{ll}\text { CFRP } \rightarrow \text { Ti drilling strategy from CFRP phase to Ti phase } \\ D & \text { drill diameter } \\ D_{\max } & \text { maximum diameter of the delamination area } \\ D_{\text {nom }} & \text { nominal hole diameter } \\ f & \text { feed rate } \\ F_{d} & \text { one-dimensional delamination factor } \\ F_{z} & \text { thrust force } \\ L & \text { total length of drill main cutting edge } \\ L_{\text {tool-CFRP }} \text { drill edge segment length of tool-CFRP interaction } \\ L_{\text {tool-Ti }} \quad \text { drill edge segment length of tool-Ti interaction } \\ M_{\mathrm{CFRP}} \quad \text { machinability of pure CFRP phase drilling } \\ M_{\mathrm{CFRP} / \mathrm{Ti}} \text { machinability of stacked CFRP/Ti interface drilling } \\ M_{\mathrm{Ti}} \quad \text { machinability of pure Ti phase drilling } \\ n & \text { spindle speed } \\ R_{a} & \text { arithmetic mean roughness } \\ R_{q} & \text { root mean squared roughness } \\ R_{z} & \text { ten point mean roughness } \\ T & \text { torque } \\ \mathrm{Ti} \rightarrow \text { CFRP drilling strategy from Ti phase to CFRP phase } \\ t_{m} \quad \text { multi-tool-work interaction time }\end{array}$

$\begin{array}{ll}v_{c} & \text { cutting speed } \\ \psi & \text { drill helix angle } \\ \Phi & \text { hole diameter } \\ \Phi_{e, C F R P} & \text { hole exit diameter of CFRP phase } \\ \Phi_{e, T i} & \text { hole exit diameter of Ti phase } \\ \Phi_{\text {nom }} & \text { nominal drill diameter } \\ \Phi_{o, \text { CFRP }} & \text { hole onset diameter of CFRP phase } \\ \Phi_{o, T i} & \text { hole onset diameter of Ti phase } \\ \phi & \text { drill point angle } \\ \eta & \text { tool-work interaction ratio } \\ \eta_{A} & \text { ratio of } L_{\text {tool-CFRP to } L} \\ \eta_{B} & \text { ratio of } L_{\text {tool-Ti }} L\end{array}$

$\begin{array}{ll}\text { Abbreviations } \\ \text { CFRP } & \text { carbon fiber reinforced polymer } \\ \text { CMM } & \text { coordinate measuring machine } \\ \text { CTF } & \text { critical thrust force } \\ \text { MFD } & \text { multifaceted drill } \\ \text { TEC } & \text { thermal expansion coefficient } \\ \text { Ti } & \text { titanium }\end{array}$

composite phase and Ti burrs in the metallic phase always prevail in the material removal process and account for a large number of part rejections. Besides, the rapid tool wear progression and premature tool failure are also a key source of increased machining costs. Specifically, it is estimated that the reasons for the majority of the rejected parts are the use of improper cutting parameters, non-optimal drill bits and unfavorable cutting environments [1].

Additionally, in hybrid CFRP/Ti stack drilling, typically two different cutting sequence strategies, i.e., drilling from CFRP $\rightarrow \mathrm{Ti}$ and from $\mathrm{Ti} \rightarrow \mathrm{CFRP}$, exist from the aspect of tool entry and tool exit throughout the chip removal process. To improve the machinability of the bi-material system, a careful selection of cutting sequence strategy is of great importance. Through one previous literature survey [1], it was understood that most scholars [9-12] have believed that the CFRP $\rightarrow$ Ti cutting sequence is often a reasonable and efficient strategy for minimizing the severe hole damage when vertical drilling of the bi-material system. Their key supporting arguments were that in such drilling sequence, a lower extent of exit delamination damage can be achieved due to the supporting role of the bottom Ti alloy in preventing laminate deflection and limiting the workpiece dynamics $[1,9]$. Further, an analytical model proposed by Qi et al. [13] for drilling FRP/metal stacks also confirmed that the FRP $\rightarrow$ metal drilling sequence usually yields a higher CTF (critical thrust force) value than that obtained in the metal $\rightarrow$ FRP drilling sequence, i.e., the FRP $\rightarrow$ metal drilling can promote a lower delamination extent as compared to its counterpart one. However, this drilling sequence itself has several inherent disadvantages. For instance, it will inevitably result in the serious difficulty of Ti chip evacuation while drilling the bottom Ti phase. Since hot, long and spiral features usually characterize the drilled-out Ti chips, it will cause severe abrasion/erosion actions on the machined CFRP phase and greatly deteriorate the hole quality. Moreover, the spiral Ti chips can easily entangle themselves with the drill margins, and cause premature tool failures like micro chipping or edge fracture. In contrast, the $\mathrm{Ti} \rightarrow$ CFRP drilling sequence is capable of promoting efficient $\mathrm{Ti}$ chip ejection and quick heat dissipation due to the short chip evacuation length involved in drilling. However, this drilling sequence is likely to induce a higher extent of delamination damage of the composite phase. To date, the majority of the previous work [9-12,14,15] concerning drilling hybrid CFRP/Ti stacks was performed solely using the CFRP $\rightarrow$ Ti drilling sequence. A comparative study to clarify the different benefits between the two cutting sequences in drilling has not yet been reported in the open literature.

With respect to the current research advances, a large amount of experimental work has been performed in the past few decades in order to improve the machinability of hybrid CFRP/Ti stacks through the use of superior tool materials [9,10,14,16,17], optimal tool geometries $[11,18,19]$ or favorable cutting environments $[18,20,21]$. At present, the main research hotspots of hybrid composite drilling as surveyed in one recent review work [1] are to (i) investigate the parametric effects on various drilling responses (drilling force, hole quality, etc.), (ii) evaluate different tool performances, and (iii) reveal the tool wear mechanisms and tool failure modes governing the bi-material drilling. In spite of the wellperformed studies, the pertinent research work regarding the aforementioned issues, e.g., machinability classification of hybrid CFRP/Ti stacks and the influences of different cutting sequence strategies on drilling, is still rarely reported.

Based on these incentives, this paper aims to carry out a series of experimental studies on drilling hybrid CFRP/Ti stacks by adopting different tool geometries/materials and drilling sequence strategies. The key objectives of present work are to reveal the machinability classification of the bi-material system through the force signal inspection, and clarify the relative effects of cutting parameters and tool geometries/materials on the bi-material drilling. A special focus was made on the evaluation of different tool performances and on the investigation of different cutting sequences' influences on drilling output. The fundamental machining responses including drilling forces, machined hole quality (e.g., surface roughness, hole diameter, and roundness error) and drillinginduced damage (e.g., delamination extent, and burr defect) were precisely addressed versus the utilized cutting conditions.

\section{Experimental procedures and drilling design}

\subsection{CFRP/Ti workpiece details}

The studied hybrid CFRP/Ti specimen was provided by VN Composites Company in France, consisting of one annealed Ti6Al4V 
Table 1

Chemical composition of Ti6Al4V alloy.

\begin{tabular}{llllllll}
\hline & $\mathrm{C}$ & $\mathrm{Fe}$ & $\mathrm{N}$ & $\mathrm{O}$ & $\mathrm{Al}$ & $\mathrm{V}$ & $\mathrm{Ti}$ \\
\hline Content (wt.\%) & $<0.08$ & $<0.25$ & $<0.05$ & 0.2 & $5.5-6.76$ & $3.5-4.5$ & Balance \\
\hline
\end{tabular}

alloy and one T300/914 CFRP laminate (60\% fiber volume fraction) subjected to the stacking sequence of $\left[45^{\circ} /-45^{\circ} / 0^{\circ} / 90^{\circ}\right]_{s}$. Each stacked phase has $4 \mathrm{~mm}$ thickness and the entire CFRP/Ti specimen has the total dimensions of $254 \mathrm{~mm}$ (length) $\times 34.5 \mathrm{~mm}$ (width) $\times$ $8 \mathrm{~mm}$ (thickness). The nominal chemical composition of the stacked Ti6Al4V alloy and the basic mechanical/physical properties of the used hybrid CFRP/Ti stack are summarized in Tables 1 and 2, respectively.

\subsection{Drill bit information}

For drilling trials, two types of standard twist drills (ISO references: 452.1-0635-044A0-CM H10F and R846-0635-50-A1A 1220) with the identical cutting diameter of $6.35 \mathrm{~mm}$, provided by Sandvik Coromant, France, were adopted for the hole making, as shown in Fig. 1. The first drill bit designated by drill $\mathrm{A}$ is an uncoated solid carbide tool with two main cutting edges, a short $0.11 \mathrm{~mm}$-length chisel edge, a small helix angle $(\psi)$ of $20^{\circ}$ and a point angle $(\phi)$ of $135^{\circ}$. In contrast, the second drill bit designated by drill B is a PVD TiAlN-coated carbide twist drill manufactured with two flutes, a long $0.22 \mathrm{~mm}$-length chisel edge, a large helix angle $(\psi)$ of $27.2^{\circ}$ and a point angle $(\phi)$ of $140^{\circ}$. The TiAlN coating can provide superior wear resistance and stable high hardness to cope with the harsh cutting conditions developed in the CFRP/Ti drilling process.

\subsection{Selection of cutting parameters}

Through the literature survey, it is reported that the optimal cutting conditions for drilling composites are high cutting speed $(150-200 \mathrm{~m} / \mathrm{min})$ and low feed rate $(0.01-0.05 \mathrm{~mm} / \mathrm{rev})$ $[21,22]$, while for Ti alloy machining, low cutting speed (10 $30 \mathrm{~m} / \mathrm{min})$ and positive feed rate $(0.05-0.1 \mathrm{~mm} / \mathrm{rev})$ are recommended $[9,23]$. As such, it leads to a compromise selection of the cutting parameters that often give rise to the serious undesirable drilling consequences (e.g., high force/heat generation, poor hole quality and severe tool wear) $[1,10]$. Moreover, since the Ti phase drilling usually causes the biggest problems, the cutting parameters used for drilling CFRP/Ti were selected to match those for the difficult-to-drill Ti6Al4V alloy. Based on this selection criterion, the cutting parameters given in Table 3 were adopted for the drilling trials.

\subsection{Experimental setup and on-site measurement}

The drilling trials of hybrid CFRP/Ti stacks were performed on a high speed, five-axis CNC machining center DMU 60 monoBLOCK under the dry cutting conditions. The basic experimental setup of the drilling work is shown in Fig. 2, in which the hybrid CFRP/Ti specimen was clamped by a fixture from the top side during

Table 2

Basic mechanical properties and configuration of the studied hybrid CFRP/Ti6Al4V specimen.

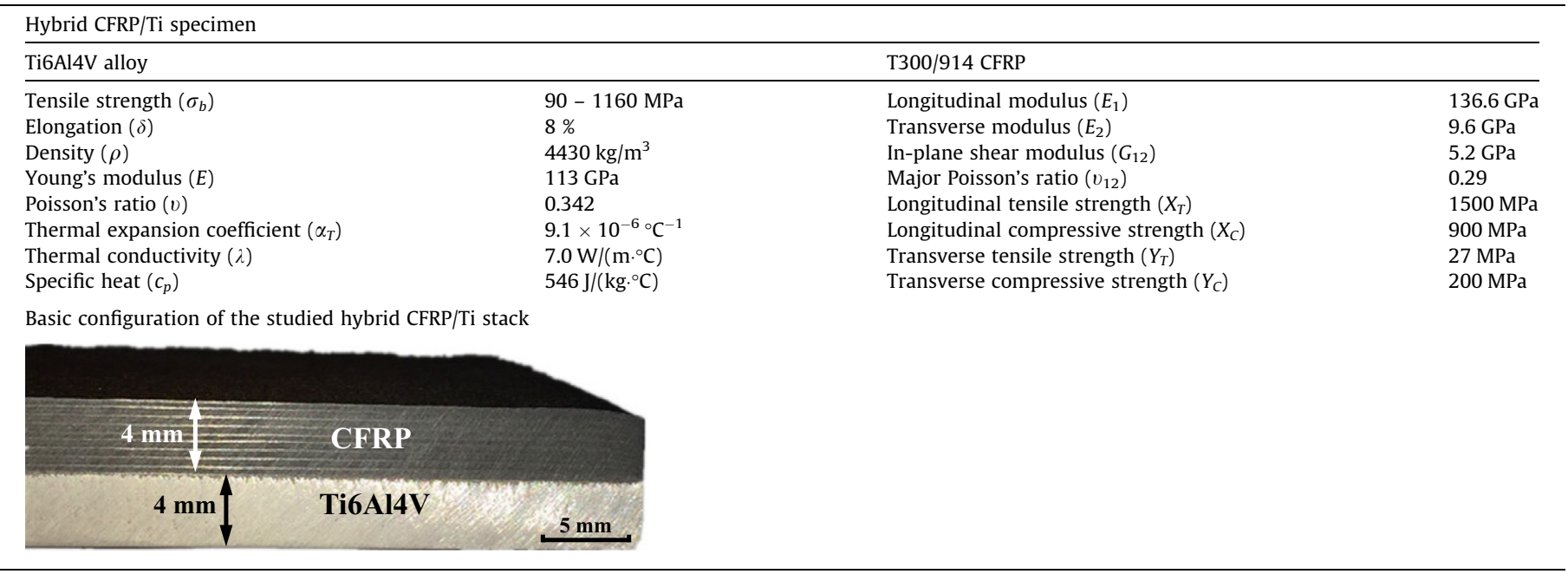
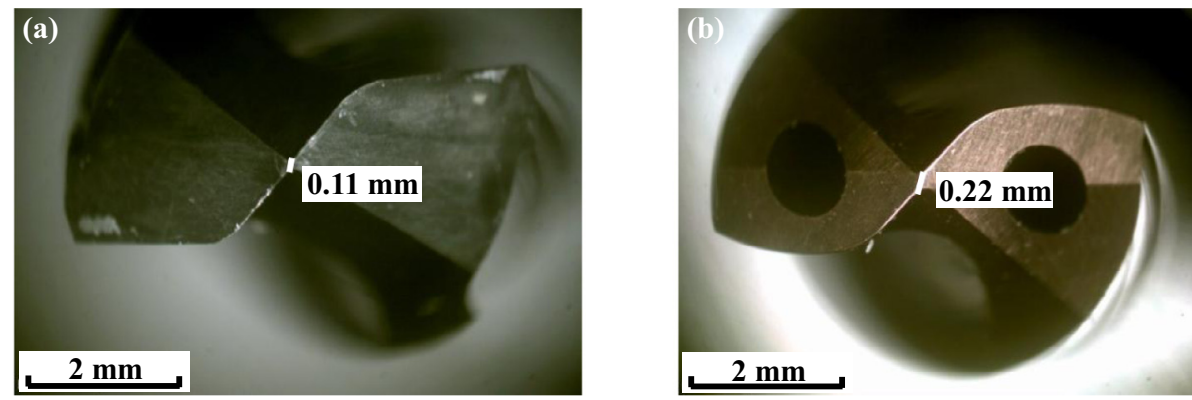

Fig. 1. Micrographs showing the drill-tip zones for the used drill bits ( $\times 30$ ): (a) drill A (uncoated solid carbide drill bit) and (b) drill B (PVD TiAIN-coated drill bit) 
Table 3

Adopted cutting parameters for hybrid CFRP/Ti stack drilling.

\begin{tabular}{llllll}
\hline Cutting parameter & Level 1 & Level 2 & Level 3 & Level 4 & Level 5 \\
\hline Cutting speed, $v_{c}(\mathrm{~m} / \mathrm{min})$ & 15 & 30 & 45 & 60 & - \\
Feed rate, $f(\mathrm{~mm} / \mathrm{rev})$ & 0.03 & 0.06 & 0.09 & 0.12 & 0.15
\end{tabular}

drilling. The entire fixture was firmly mounted on a piezoelectric Kistler dynamometer (type 9271A) for measuring the generated thrust force $\left(F_{z}\right)$ and torque $(T)$ signals in chip removal process. A multichannel charge amplifier (type 5019A130) connected to a data acquisition board was utilized to convert the drilling signals into voltage signals. Afterward, the LabVIEW Signal Express software (National Instruments, USA) was employed to plot the recorded data and calculate the average values of the force signals. Note that in the drilling operation, two different cutting sequence strategies were also implemented throughout the experimental investigations. The used cutting conditions for hybrid CFRP/Ti drilling with respect to the adopted cutting sequence strategies and applied drill bits are summarized in Table 4.

\subsection{Post-treatment analysis}

After the experimental completion, hole dimensional features including hole diameter and roundness error were measured on a Mitutoyo BHN506 Coordinate Measuring Machine (CMM) with the use of a steel-made ruby roll of $1 \mathrm{~mm}$ tip radius (type A5000-7806) at various locations, as shown in Fig. 3. The measurement was made separately on each stacked layer. For each stacked phase, two measurements were performed on the hole sides with $1 \mathrm{~mm}$ from hole onset and $1 \mathrm{~mm}$ from hole exit, which were respectively marked as $\Phi_{o}$ and $\Phi_{e}$.

For surface finish evaluation, the most-used surface roughness indicators $\left(R_{a}\right.$ - arithmetic mean roughness, $R_{q}$ - root mean

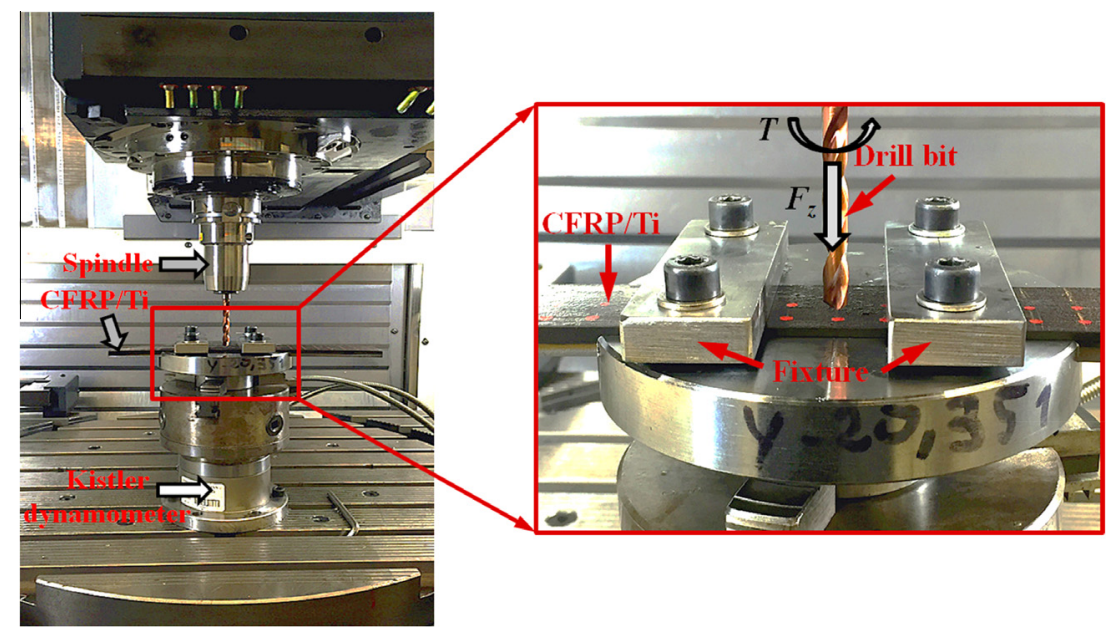

Fig. 2. Experimental setup for drilling hybrid CFRP/Ti stacks (CFRP $\rightarrow$ Ti drilling sequence).

Table 4

Summary of the test number and used cutting conditions for CFRP/Ti drilling.

\begin{tabular}{|c|c|c|c|c|}
\hline \multicolumn{5}{|c|}{ Drilling trial } \\
\hline Test No. & Cutting speed, $v_{c}(\mathrm{~m} / \mathrm{min})$ & Spindle speed, $n$ (rpm) & Feed rate, $f(\mathrm{~mm} / \mathrm{rev})$ & Cutting sequence and drill bit \\
\hline $1-5$ & 15 & 752 & $0.03,0.06$ & $\mathrm{CFRP} \rightarrow \mathrm{Ti}(\Phi 6.35 \mathrm{~mm})$ \\
\hline $6-10$ & 30 & 1504 & $0.09,0.12$ and 0.15 & Drill A and drill B \\
\hline $11-15$ & 45 & 2256 & & \\
\hline $16-20$ & 60 & 3008 & & \\
\hline $1-5$ & 15 & 752 & $0.03,0.06$ & $\mathrm{Ti} \rightarrow \operatorname{CFRP}(\Phi 6.35 \mathrm{~mm})$ \\
\hline $6-10$ & 30 & 1504 & $0.09,0.12$ and 0.15 & Drill B (TiAlN coating) \\
\hline $11-15$ & 45 & 2256 & & $\longrightarrow$ \\
\hline $16-20$ & 60 & 3008 & & \\
\hline
\end{tabular}

Scheme of the drilled hole distribution in the hybrid CFRP/Ti specimen
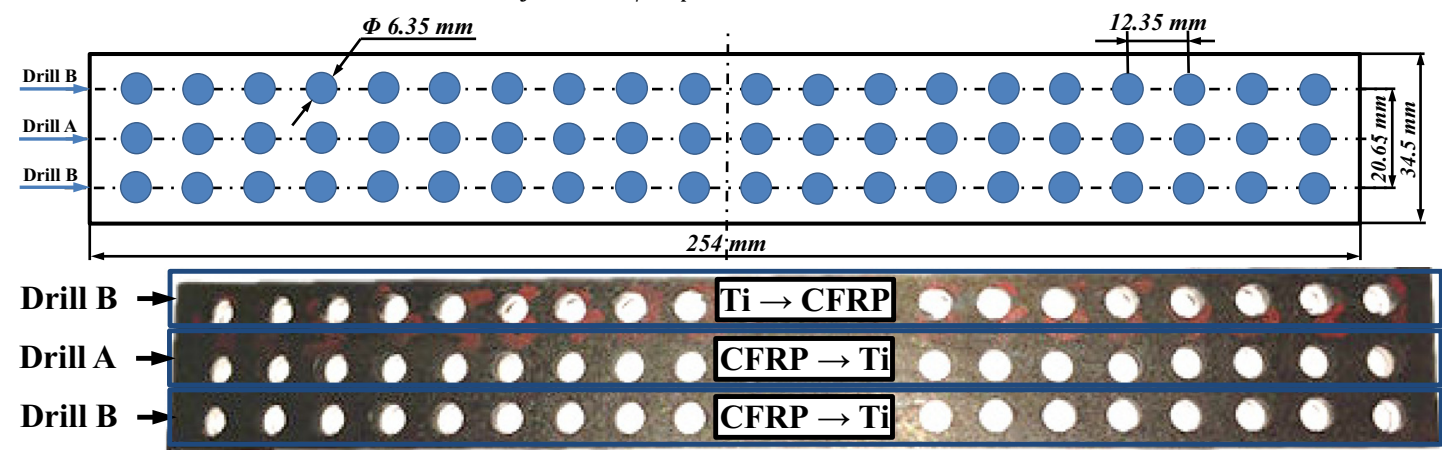


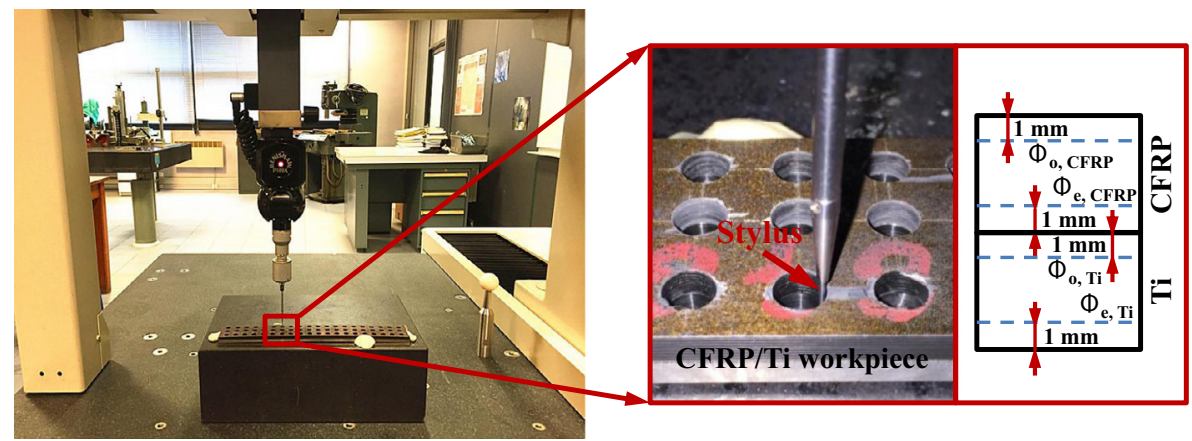

Fig. 3. Photograph showing the process setup of hole dimensional feature measurement.

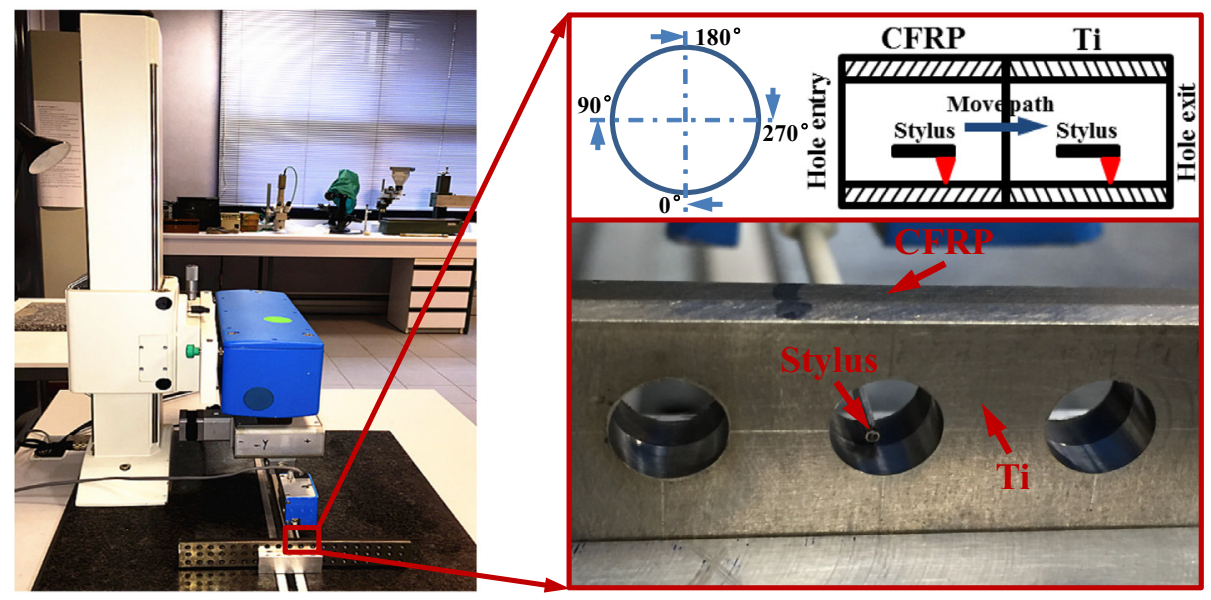

Fig. 4. Process setup of the surface roughness measurement for drilled CFRP/Ti holes.

squared roughness, and $R_{z}$ - ten point mean roughness) were adopted for all drilled holes. The surface roughness measurement was made on each material layer by using the Hommel Wave surface profilometer with a diamond stylus of $2 \mu \mathrm{m}$ tip radius and a cut-off length of $0.8 \mathrm{~mm}$, as shown in Fig. 4. A total evaluation length of $3 \mathrm{~mm}$ was set in the built-in software of the surface profilometer for each hole surface of stacked layers along the drilling direction.

The resected chip type and exit hole edge morphology of each stacked phase were recorded by using the Nikon tool maker's SMZ-2T microscope with the magnifications ranging from $\times$ 10 to $\times 120$. Afterward, the drilling-induced damage (delamination defect and burr width) was measured by the help of the built-in software (OmniMet Images \& Measures, Buehler ${ }^{\infty}$, USA) linked to the SMZ-2T microscope. Each measurement was repeated three times under the identical conditions so as to get reliable results.

\section{Results and discussion}

\subsection{Drilling process and force signal characterization}

The drilling force signals developed in function of cutting time can be utilized as an effective method to monitor the status of the on-site tool-work interaction. In hybrid CFRP/Ti stack drilling, the most complicated cutting stage usually takes place in the bimaterial interface (aka "CFRP-to-Ti" contact boundary) due to the occurrence of the coupled composite-metal drilling process. Fig. 5 shows the scheme of the drill tip position involved in the $\mathrm{CFRP} / \mathrm{Ti}$ interface drilling under the cutting sequence of CFRP $\rightarrow$

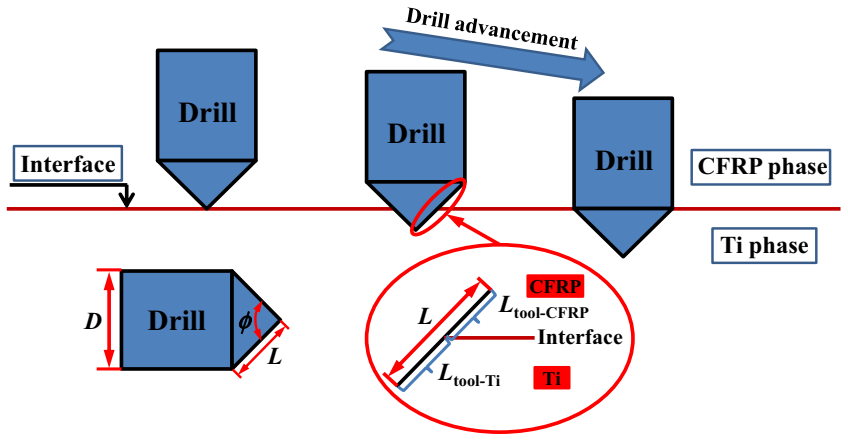

Fig. 5. Scheme of the drill tip position involved in CFRP/Ti interface drilling (CFRP $\rightarrow$ Ti cutting sequence).

$\mathrm{Ti}$, in which the drill main cutting edge is simplified as a straight line for easy interpretation. As can be seen from this figure, when the drill tip initially attacks the interface zone, the previous pure tool-CFRP interaction is gradually transformed into a multi-toolwork interaction.

The drill main cutting edge is then separated into two key segments that are responsible for tool-CFRP interaction and tool-Ti interaction, respectively. Considering that the total length of the drill main cutting edge is $L$, the corresponding edge segments for tool-CFRP interaction and tool-Ti interaction can be designated as $L_{\text {tool-CFRP }}$ and $L_{\text {tool-Ti, }}$, respectively. Besides, the ratios of the segments of the tool-work interactions ( $L_{\text {tool-CFRP }}$ and $\left.L_{\text {tool-Ti }}\right)$ to the 
total drill main cutting edge length $(L)$ can be respectively defined as follows.

$\eta_{A}=\frac{L_{\text {tool-CFRP }}}{L} \in[0,1]$

$\eta_{B}=\frac{L_{\text {tool }-T \mathrm{i}}}{L} \in[0,1]$

where $\eta_{A}=0$ and $\eta_{B}=0$ indicate the inexistence of tool-CFRP interaction and tool-Ti interaction, respectively; $\eta_{A}=1$ and $\eta_{B}=1$ signify the full tool-CFRP interaction and full tool-Ti interaction, respectively.

With the ongoing drilling advancement, both $\eta_{A}$ and $\eta_{B}$ values change dynamically within the interval range of $\eta \in[0,1]$, greatly dependent on the implemented drilling sequences. During the interface cutting, the combined chip separation modes including brittle fracture and elastic-plastic deformation should simultaneously take place along the main cutting edges and then result in the coupled CFRP chip and Ti chip formation. Moreover, the total cutting time $\left(t_{m}\right)$ governing the interface drilling can be roughly estimated through the following equation [1].

$t_{m}=\frac{D}{2 n f} \cot \frac{\phi}{2}$

where $D$ is the used drill diameter; $\phi$ is drill point angle; $n$ and $f$ are spindle speed and feed rate, respectively. As shown in this equation, drill point angle $(\phi)$ has a negative impact on the interface drilling duration $\left(t_{m}\right)$, i.e., an increased $\phi$ commonly reduces the $t_{m}$ duration.

Considering the one-shot drilling cycle of hybrid CFRP/Ti stack machining, the total drilling process can be specified in terms of tool-work interaction ratio $(\eta)$ versus the cutting time $(t)$ from the aspects of hole entry and hole exit, as shown schematically in Fig. 6. Note that in Fig. 6, $L_{1}$ and $L_{2}$ represent the individual workpiece thickness of the CFRP phase and Ti phase, respectively; $t_{1}-t_{5}$ are the representative time frames of different cutting stages involved in CFRP/Ti drilling and can be defined as follows.

$$
\left[\begin{array}{c}
t_{1} \\
t_{2} \\
t_{3} \\
t_{4} \\
t_{5}
\end{array}\right]=\left[\begin{array}{c}
\frac{D}{2 n f} \cot \frac{\phi}{2} \\
\frac{L_{1}}{n f} \\
\frac{L_{1}}{n f}+\frac{D}{2 n f} \cot \frac{\phi}{2} \\
\frac{L_{1}+L_{2}}{n f} \\
\frac{L_{1}+L_{2}}{n f}+\frac{D}{2 n f} \cot \frac{\phi}{2}
\end{array}\right],\left(L_{1}, L_{2}>\frac{D}{2} \cot \frac{\phi}{2}\right)
$$

As depicted in Fig. 6, when the drill tip initially penetrates into the CFRP phase, the $\eta_{A}$ parameter experiences a quick elevation through the drilling duration of $t \in\left[0, t_{1}\right]$, which signifies the gradual engagement of the pure tool-CFRP interaction. With the tool advancement, particularly when the drill cutting edges are fully involved in the CFRP phase machining (stage $b-c$ ), the $\eta_{A}$ parameter maintains the maximum value of 1 until the drill tip cuts into the interface zone. Since in such drilling status, the $\eta$ equal to 1 indicates the full tool-CFRP interaction, the cutting stage $b-c$ can be considered as a steady drilling process due to the full engagement of tool cutting edges in drilling. After the completion of the pure tool-CFRP interaction $\left(t \in\left[0, t_{2}\right]\right)$, the drill edges are gradually involved in the interface cutting, in which the $\eta_{B}$ parameter increases gradually from zero while the $\eta_{A}$ parameter suffers a decreasing trend. The phenomena indicate the occurrence of the multi-tool-work interaction dominating the chip separation process. In such circumstance, the drill cutting edges should undergo a coupled composite-metal chip removal mode and result in the combined "powdery"-like and "continuous"-like chip formation. Since the $\eta_{A}$ and $\eta_{B}$ parameters vary dynamically with cutting time, the cutting edges will inevitably experience a severe transition of drilling-induced mechanical/thermal responses. For instance, the disparate machinability behaviors of the CFRP and Ti phases will induce different levels of force generation and cutting temperature, and hence result in the uneven stress/heat distribution on the drill cutting edges, which may cause the instability of the drilling process and initiate serious tool catastrophic failure. Since in such drilling stage, the main cutting edges experience a combined CFRP/Ti material removal process, the cutting duration of $t \in\left[t_{2}, t_{3}\right]$ (aka cutting stage $c-d$ ) in reality can reflect the machinability of the stacked CFRP/Ti interface drilling $\left(M_{\mathrm{CFRP} / \mathrm{Ti}}\right)$. Moreover, when the drill edges completely cut into the Ti phase, the previous multitool-work interaction is eventually transformed into the pure tool-Ti interaction. And elastic-plastic deformation then acts as a predominant chip separation mode governing the hybrid composite stack drilling. In such case, the $\eta_{B}$ parameter keeps a constant maximum value of 1 and the drilling stage $d-e\left(t \in\left[t_{3}, t_{4}\right]\right)$ can be identified as a steady cutting process as shown in Fig. 6. Finally, when the drill tip penetrates into the exit boundary of the Ti phase, the pure tool-Ti interaction ratio $\left(\eta_{B}\right.$ parameter) decreases quickly into zero until the completion of the drilling operation. The drilling stage $d-f$ then reflects the machinability of the individual Ti phase $\left(M_{\mathrm{Ti}}\right)$.
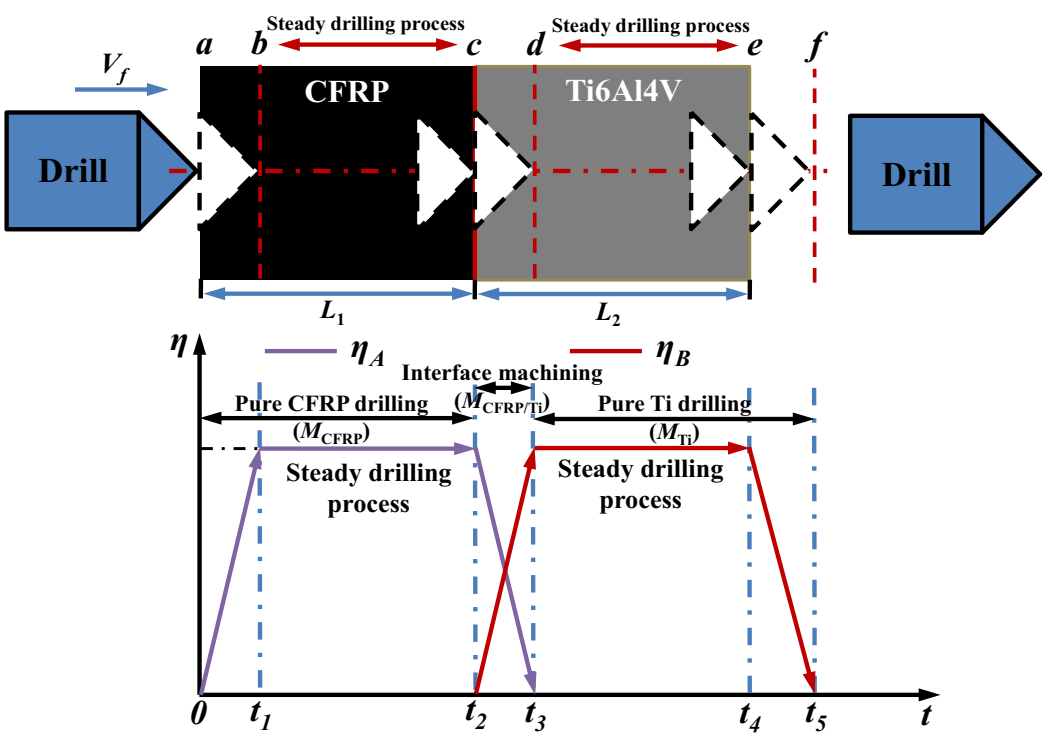

Fig. 6. Scheme of the tool-work interaction ratio $(\eta)$ versus cutting time $(t)$ in drilling hybrid CFRP/Ti stacks (CFRP $\rightarrow$ Ti cutting sequence strategy). 

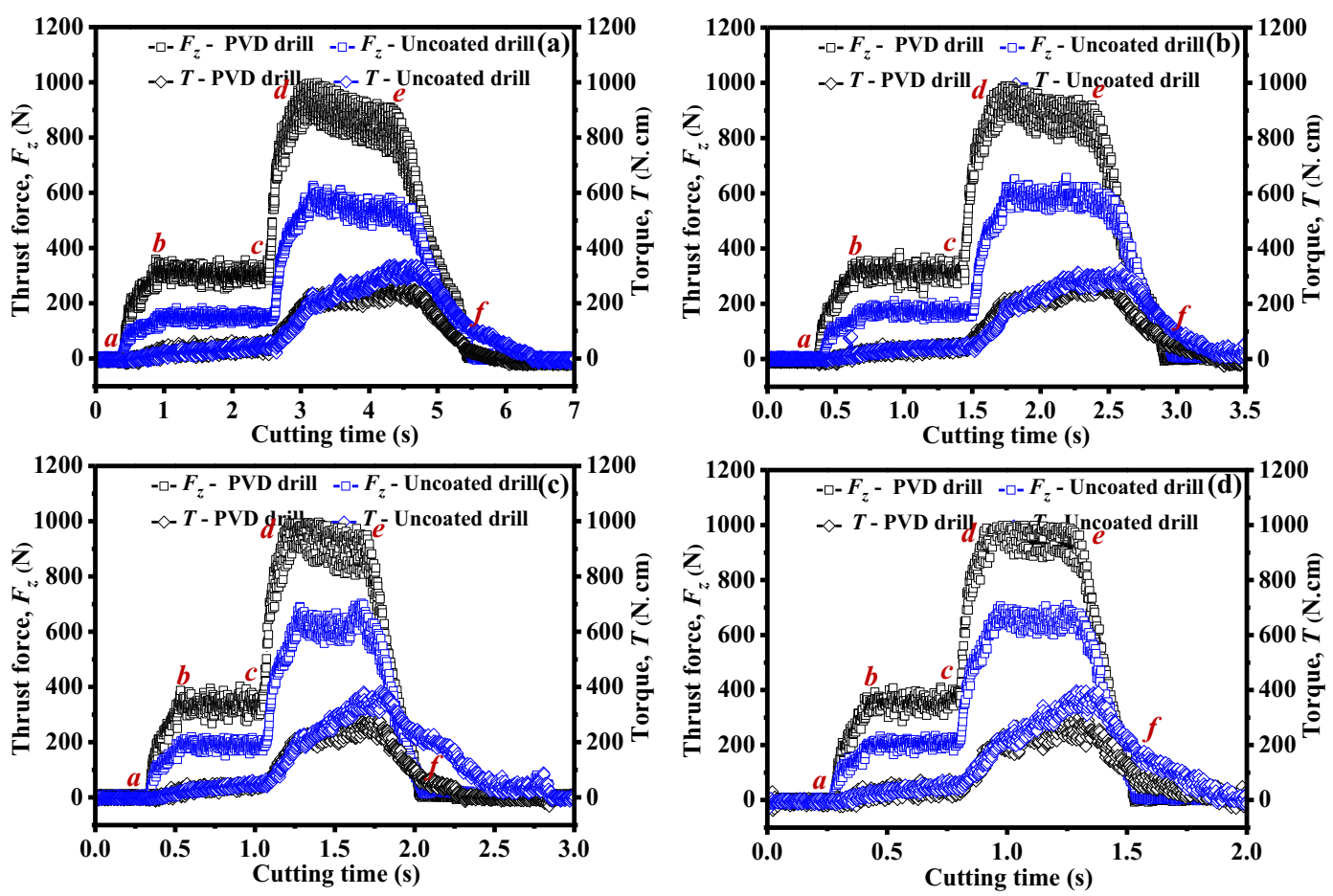

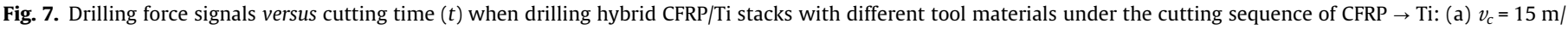
$\mathrm{min}, f=0.15 \mathrm{~mm} / \mathrm{rev}$, (b) $v_{c}=30 \mathrm{~m} / \mathrm{min}, f=0.15 \mathrm{~mm} / \mathrm{rev}$, (c) $v_{c}=45 \mathrm{~m} / \mathrm{min}, f=0.15 \mathrm{~mm} / \mathrm{rev}$, and (d) $v_{c}=60 \mathrm{~m} / \mathrm{min}, f=0.15 \mathrm{~mm} / \mathrm{rev}$.

To better monitor the on-site status of the tool-work interactions dominating the hybrid CFRP/Ti stack machining, the drilling force signal in function of cutting time $(t)$ was utilized as an effective method to facilitate the drilling comprehension, as shown in Fig. 7. Note that in Fig. 7, the comparative drilling force signals were decomposed into two main components, i.e., thrust force signal $\left(F_{z}\right)$ and torque signal $(T)$, that were obtained under the identical CFRP $\rightarrow$ Ti cutting sequence. A comparative result of the force signals developed by two different drill bits (drill A and drill B) is presented. It is noticeable that the total drilling force signals can be classified into five cutting stages $(a \rightarrow b \rightarrow c \rightarrow d \rightarrow e \rightarrow f)$ for all the tested drill bits and cutting parameters, which signify the different statuses of the tool-work interactions governing the drilling operation as elaborated earlier. In addition, the force signal profiles captured in the current study also show a similar pattern with the experimental observation gained by Ramulu et al. [9] when drilling hybrid $(\mathrm{Gr} / \mathrm{Bi}) / \mathrm{Ti}$ stacks. Besides, the force profiles $\left(F_{z}\right.$ and $\left.T\right)$ generated in the Ti phase drilling always yield much higher magnitudes than those of the force profiles gained in the CFRP phase drilling, regardless of the implemented cutting conditions. The reason can be attributed to the high mechanical/physical properties of the titanium alloy and its specific chip removal mechanism, i.e., elastic-plastic deformation [24,25]. Further, when the drill edges cut across the CFRP/Ti interface region, a sudden increase of drilling forces is identified in the force profile $c-d$ as shown in Fig. 7, which will result in the instability of the toolwork interaction dominating the chip removal process. Additionally, the force comparisons between drill A and drill B also show that under the identical cutting conditions, the PVD TiAlN-coated drill (drill B) promotes much higher force magnitudes than its counterpart one (drill A), especially for the thrust force component $\left(F_{z}\right)$ as illustrated in Fig. 7. The TiAlN-coated drill in reality should induce lower drilling forces as compared to the uncoated one due to the effective role of the TiAlN coating in anti-abrasion and antifriction. However, a higher thrust force $\left(F_{z}\right)$ is still obtained throughout both CFRP phase drilling and Ti phase drilling. Such abnormal phenomena can be explained as follows. The thrust force magnitudes developed in drilling are highly dependent on the competition between the influences of tool material composition and tool geometrical feature when fixed drilling parameters are applied. Since drill B has a longer chisel edge length of $0.22 \mathrm{~mm}$ which is approximately 2 times than that of drill $A$, the severe extrusion deformation action (aka "negative rake angle cutting") caused by the longer chisel edge length for chip removal in drill B should make a more significant contribution to the force development in contrast with drill main cutting edges. In addition, drill $\mathrm{B}$ also has a larger point angle and a larger helix angle than drill $\mathrm{A}$. For a large point angle in drill $\mathrm{B}$, it will inevitably decrease the sharpness of drill main cutting edges and increase the nominal chip layer thickness for chip separation. Besides, the larger helix angle for drill B will also increase the proportion of thrust force in the nominal force generation promoted by the drill marginal edges. Consequently, a higher thrust force $\left(F_{z}\right)$ is generated by drill $B$ when drilling CFRP/Ti stacks under the identical cutting conditions. The phenomena probably indicate that when drilling hybrid CFRP/Ti stacks, the tool geometrical features should play a more predominant role in affecting drilling forces than tool material composition.

Furthermore, the comparative drilling signals obtained in two different cutting sequence strategies when using the identical drill $\mathrm{B}$ are depicted in Fig. 8. It is clear that the drilling force signals promoted in either CFRP $\rightarrow$ Ti cutting sequence or Ti $\rightarrow$ CFRP cutting sequence show the similar five cutting stages as discussed earlier, but vary in an opposite direction. Specifically, the $\mathrm{Ti} \rightarrow$ CFRP drilling is observed to generate a little bit lower force magnitudes than those promoted in the CFRP $\rightarrow$ Ti cutting sequence, particularly for the thrust force $\left(F_{z}\right)$. Considering that the identical fresh drill bit was used for each drilling sequence and the tool wear extent was minor, the reasonable explanation can be that the Ti chip evacuation has certain influences on the drilling force measurement. This is because when operated in $\mathrm{Ti} \rightarrow$ CFRP cutting sequence, the spiral Ti chips can be quickly transported from the top Ti holes and hence will result in a negligible influence on the force signal measurement. In contrast, the CFRP $\rightarrow \mathrm{Ti}$ drilling usually leads to a 

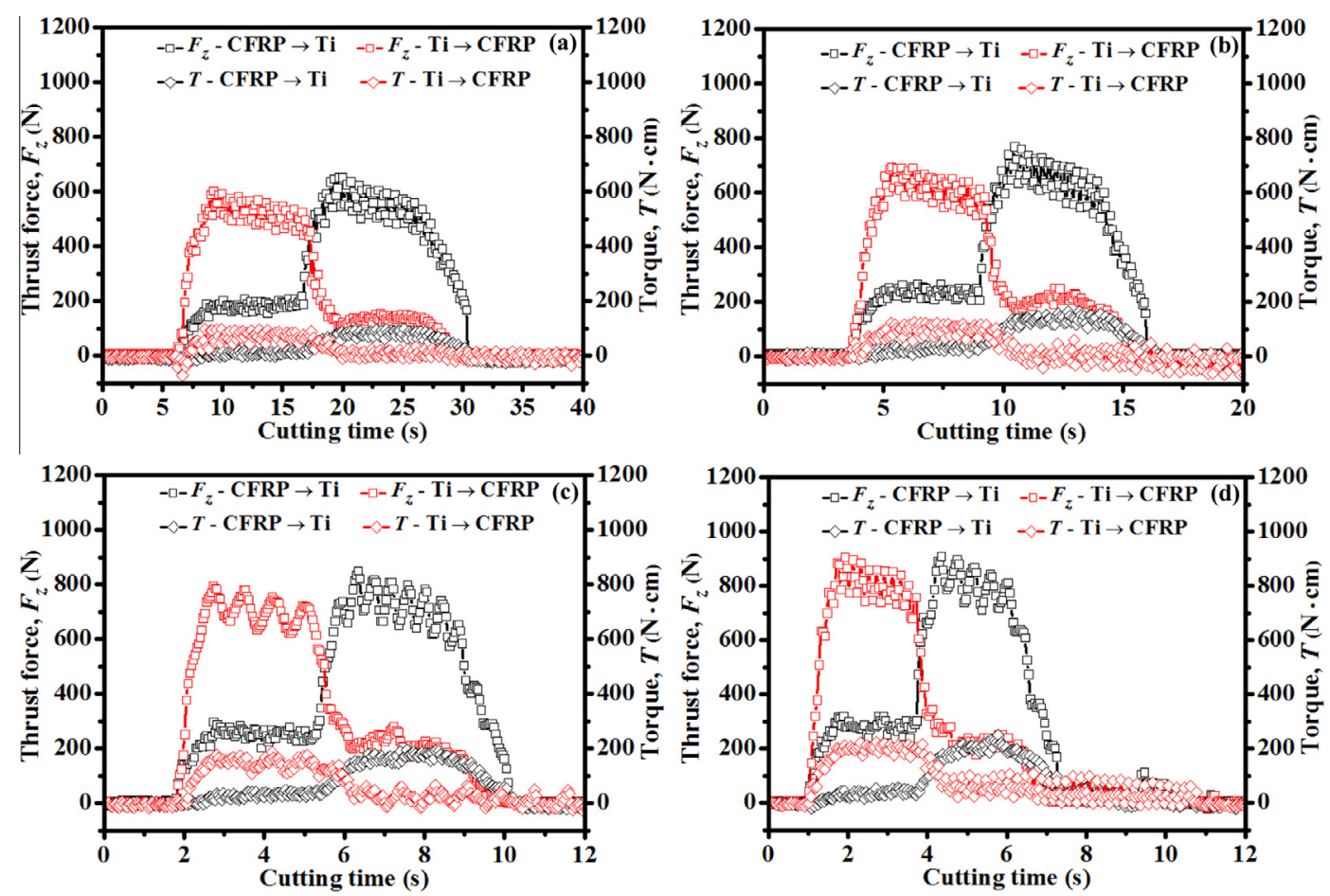

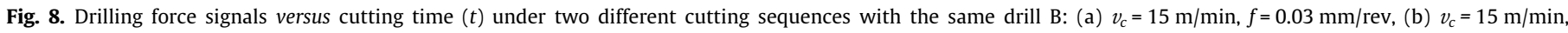
$f=0.06 \mathrm{~mm} / \mathrm{rev}$, (c) $v_{c}=15 \mathrm{~m} / \mathrm{min}, f=0.09 \mathrm{~mm} / \mathrm{rev}$, and (d) $v_{c}=15 \mathrm{~m} / \mathrm{min}, f=0.12 \mathrm{~mm} / \mathrm{rev}$.

long-time and difficult Ti chip evacuation from the machined bottom Ti holes, which will inevitably cause severe scratching effects on the drilled CFRP hole wall surfaces and hence may affect the force measurement.

Through the above analyses, the CFRP/Ti drilling operation in both CFRP $\rightarrow$ Ti cutting sequence and $\mathrm{Ti} \rightarrow$ CFRP cutting sequence can be classified into five basic cutting stages in terms of the status of tool-work interaction, as summarized in Table 5.

\subsection{Drilling force magnitudes}

To clarify the parametric effects on the force generation when drilling hybrid CFRP/Ti stacks, Figs. 9-11 show the obtained force evolution in terms of different drill bits and cutting sequence strategies. Note that the force magnitudes presented in the aforementioned figures were measured on each phase drilling and calculated based on the mean values of the steady drilling stages $\left(\eta_{A}=1\right.$ or $\left.\eta_{B}=1\right)$. As shown in these figures, the feed rate $(f)$ is confirmed to have a significantly positive impact on the drilling force magnitudes $\left(F_{z}\right.$ and $\left.T\right)$ in the case of all drill bits and cutting sequence strategies. An increase of $f$ usually gives rise to the dramatically elevated $F_{z}$ and $T$. The observation agrees with the experimental results of Ramulu et al. [9], Kim and Ramulu [26] when drilling composite/titanium stacks. The reason can be due to the increase in chip cross-sectional area (i.e., increased chip stiffness) as $f$ is elevated, which will greatly increase the cutting resistance

Table 5

Summary of the drilling stages and machinability classification when drilling hybrid CFRP/Ti stacks.

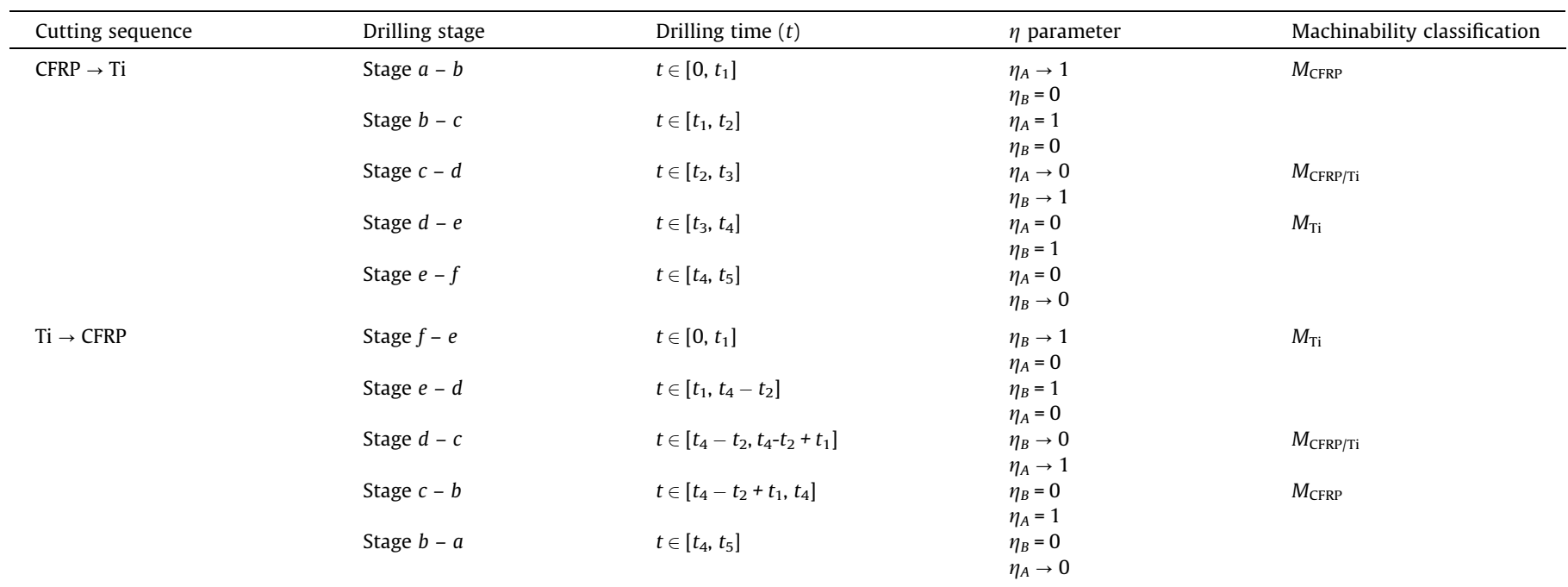

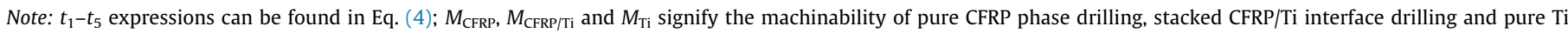
phase drilling, respectively. 


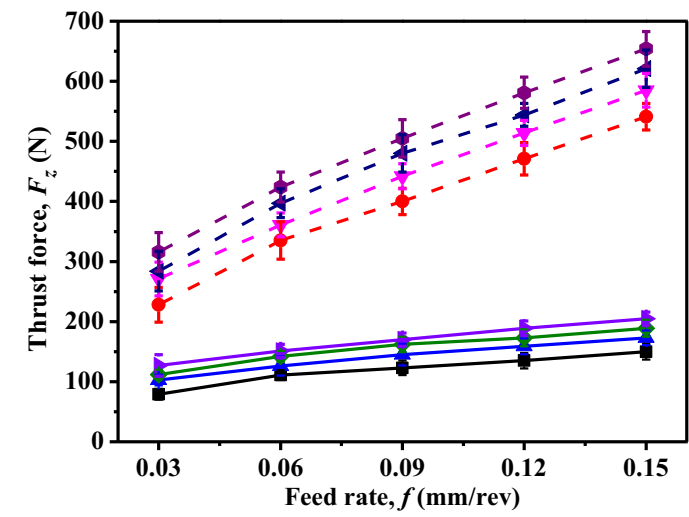

(a)

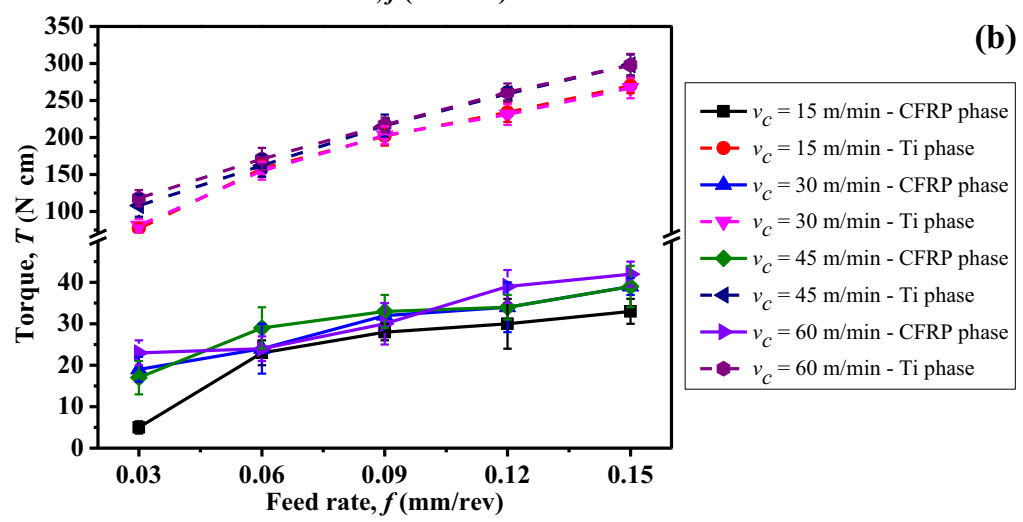

Fig. 9. Parametric effects on drilling forces when drilling hybrid CFRP/Ti stacks with drill A in the CFRP $\rightarrow$ Ti cutting sequence: (a) thrust force $\left(F_{z}\right)$ and $(b)$ torque $(T)$.

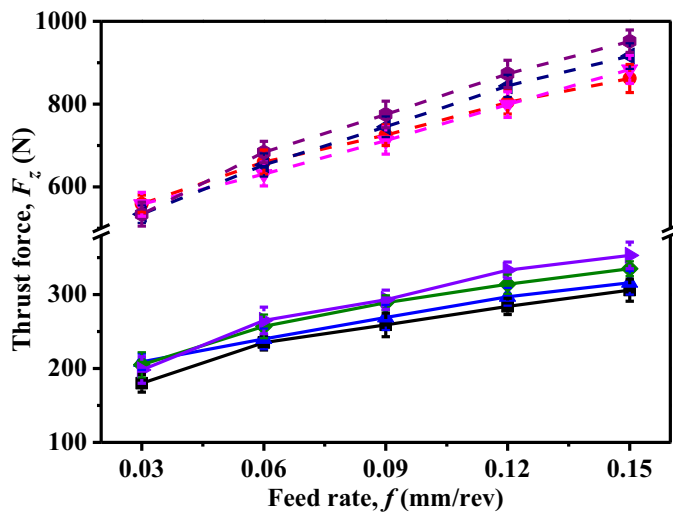

(a)

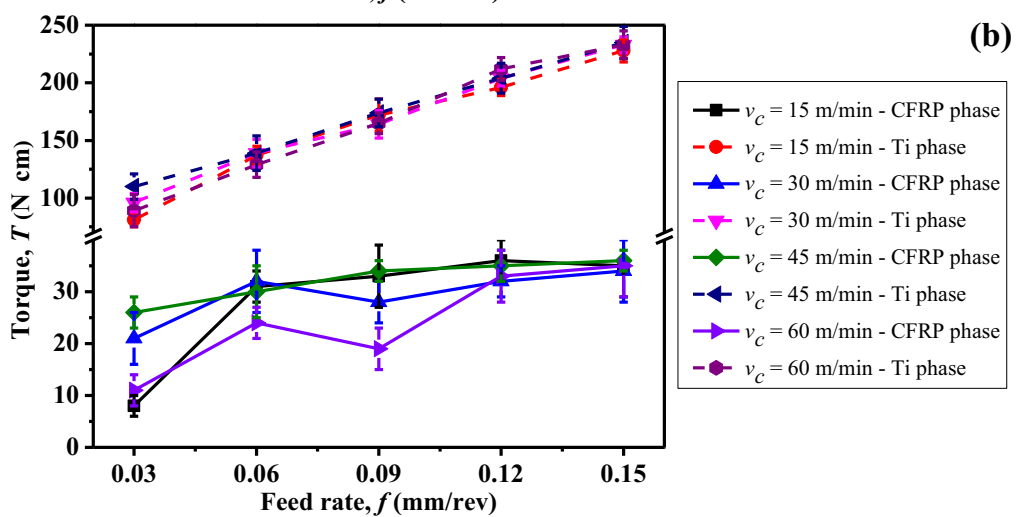

Fig. 10. Parametric effects on drilling forces when drilling hybrid CFRP/Ti stacks with drill B in the CFRP $\rightarrow$ Ti cutting sequence: (a) thrust force $\left(F_{z}\right)$ and $(b)$ torque $(T)$.

for chip breakage and hence lead to the larger drilling forces. Besides, the impact of cutting speed on drilling force magnitudes is also found to be positive in either Ti phase drilling or CFRP phase drilling but less comparable to the feed rate. These findings show a good agreement with the observation of Ramulu et al. [9] when drilling composite/titanium stacks by using HSS drills. However, 


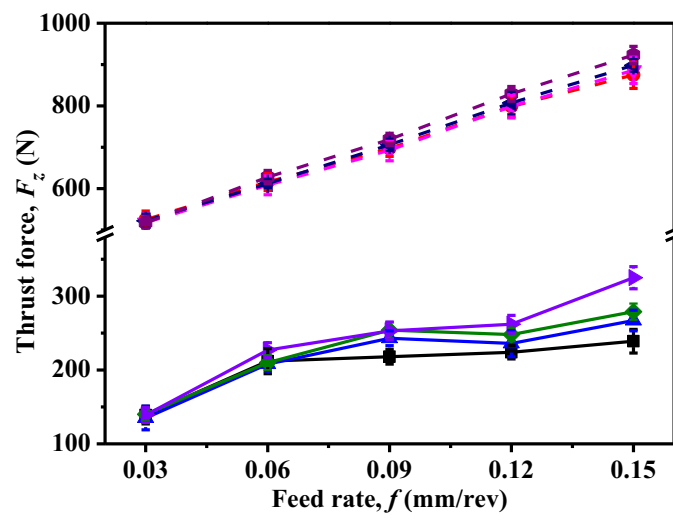

(a)

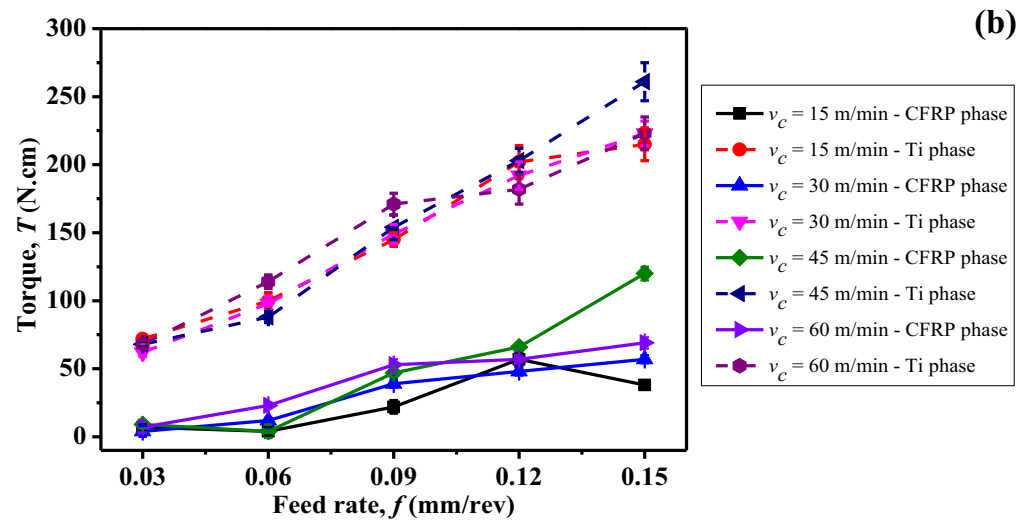

Fig. 11. Parametric effects on drilling forces when drilling hybrid CFRP/Ti stacks with drill B in the Ti $\rightarrow$ CFRP cutting sequence: (a) thrust force $\left(F_{z}\right)$ and (b) torque $(T)$.

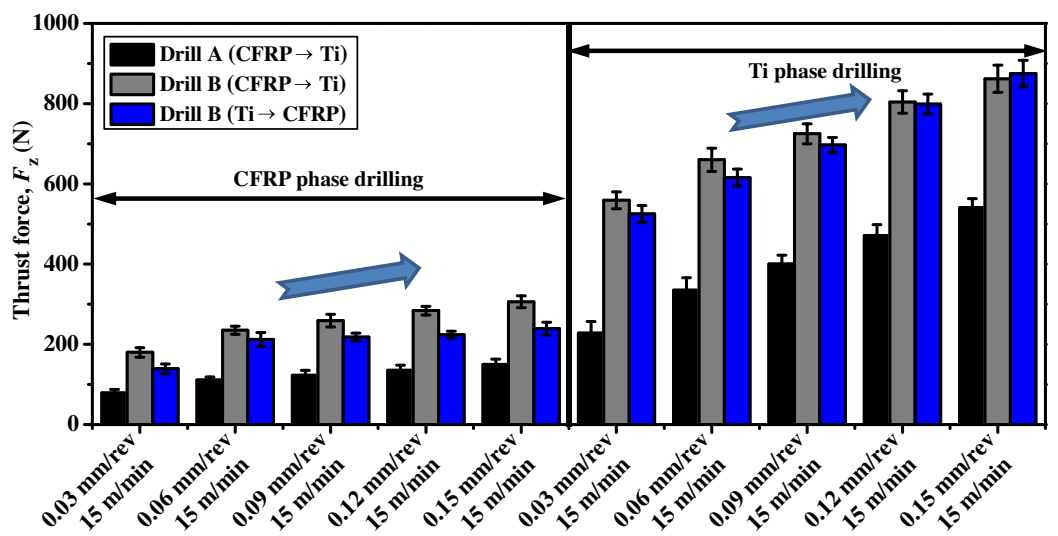

Fig. 12. Comparative $F_{z}$ magnitudes among different drill bits and cutting sequence strategies at different feed rates.

for some other studies [26,27], it is usually observed that the increased cutting speed (or spindle speed) commonly facilitates the reduction of thrust force and torque (particularly for drilling metal phase) when drilling hybrid composite stacks. The different observations between present investigation and the mentioned studies $[26,27]$ probably indicate that in the tested cutting speed range, the increased cutting temperature with elevated $v_{c}$ approximately has less significant effects on softening the work material than on tool wear progression. In addition, the experimental results also show that for minimizing the drilling forces, an optimal combination of low feed rate $(f)$ and low cutting speed $\left(v_{c}\right)$ should be adopted when drilling hybrid CFRP/Ti stacks.

Further, Figs. 12 and 13 also depict the comparative $F_{z}$ and $T$ magnitudes among different drill bits and cutting sequence strategies at various feed rates. The results confirm the signifi- cantly positive impact of $f$ on $F_{z}$ and $T$ components as discussed earlier. Additionally, the uncoated drill $\mathrm{A}$ is observed to promote the lowest thrust force $\left(F_{z}\right)$ in contrast with the TiAlN-coated drill $\mathrm{B}$ when operated in either $\mathrm{CFRP} \rightarrow \mathrm{Ti}$ cutting sequence or $\mathrm{Ti} \rightarrow$ CFRP cutting sequence under the same cutting parameters. For torque $(T)$ component, the phenomenon is not fully noticeable, particularly for the Ti phase drilling. Nevertheless, such findings agree well with the previous force-signal observation in Section 3.1. This evidence further confirms the more predominant role of tool geometrical feature (i.e., chisel edge length, point angle and helix angle) in affecting the drilling forces than the tool material composition. Finally, the $\mathrm{Ti} \rightarrow$ CFRP cutting sequence is also found to globally generate lower force magnitudes $\left(F_{z}\right.$ and $T)$ as compared to the CFRP $\rightarrow$ Ti drilling for drill B as shown in Figs. 12 and 13. 


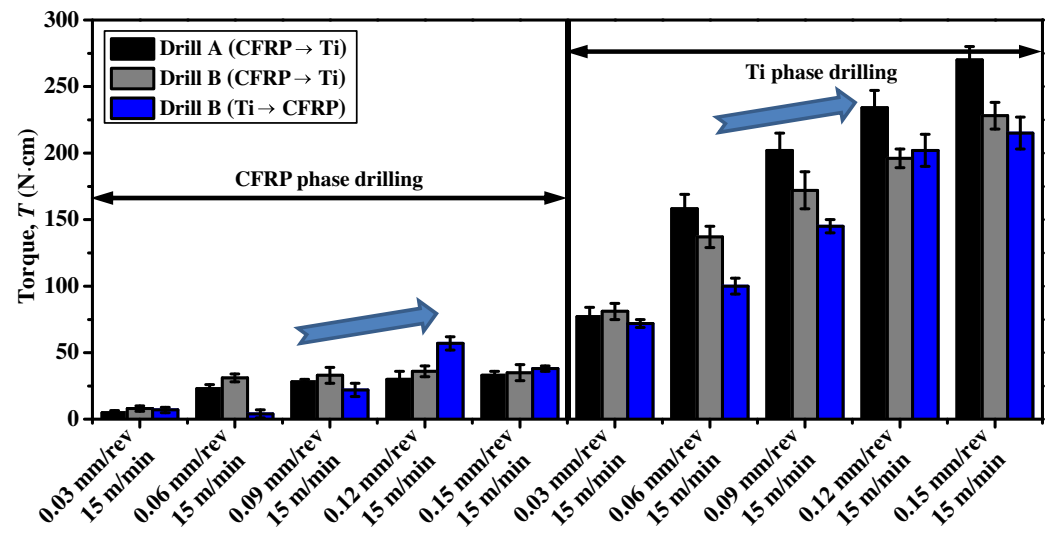

Fig. 13. Comparative $T$ magnitudes among different drill bits and cutting sequence strategies at different feed rates.

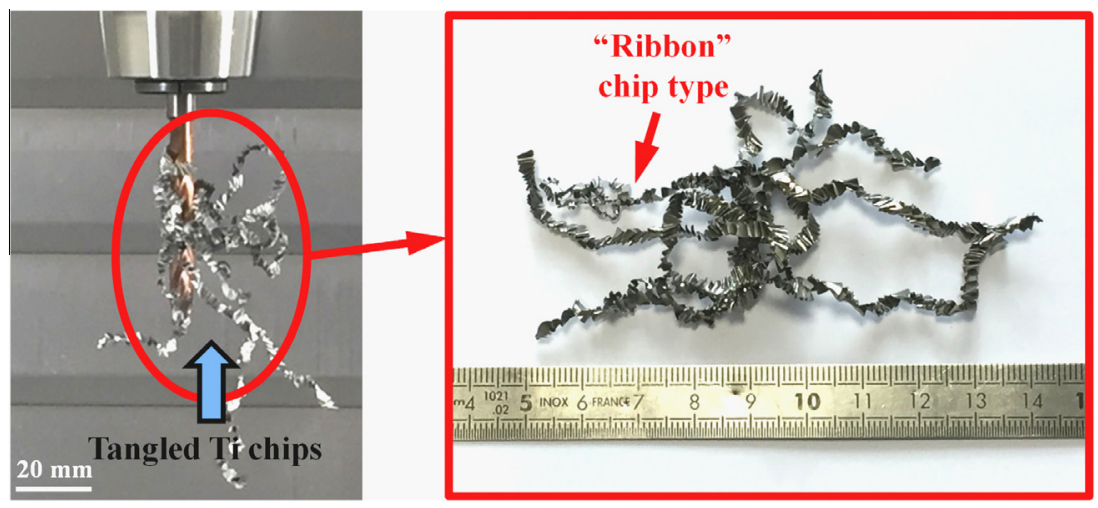

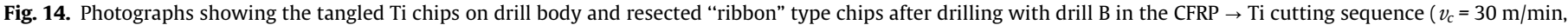
$f=0.03 \mathrm{~mm} / \mathrm{rev}$ )

\subsection{Analysis of chip type in drilling}

In hybrid composite stack drilling, an excellent chip breakability of the metallic phase is often required to cut chips into segments aiming to solve the chip tangling problem on drill flutes and to minimize the detrimental effects of chip evacuation on drilled hole wall surface. To evaluate the chip breakability in drilling hybrid CFRP/Ti stacks, a comparative investigation among different drill bits and cutting parameters was conducted. Since the CFRP chips were resected in the form of "powdery" dust that was difficult to gather, only the separated Ti chips were collected. As shown in Fig. 14, when drilling is operated under low feed-rate conditions (e.g., $f=0.03 \mathrm{~mm} / \mathrm{rev}$ ) with drill B, typically long and ribbon type Ti chips are produced and tangled along the drill body. It is worth mentioning that the occurrence of such phenomenon, on one hand, will cause severe abrasion/erosion effects on the drilled hole surfaces and deteriorate the drilled surface finish; on the other hand, it will accelerate the incidence of premature tool failures like micro chipping, edge fracture or coating peeling.

Furthermore, Figs. 15 and 16 also show the representative Ti chips produced in drilling of CFRP/Ti stacks when using different drill bits at various feed rates and cutting speeds, respectively. It is apparent that for drill $\mathrm{A}$ in the CFRP $\rightarrow$ Ti cutting sequence, the resected chips are of mixed type, partly ribbon type and rest are

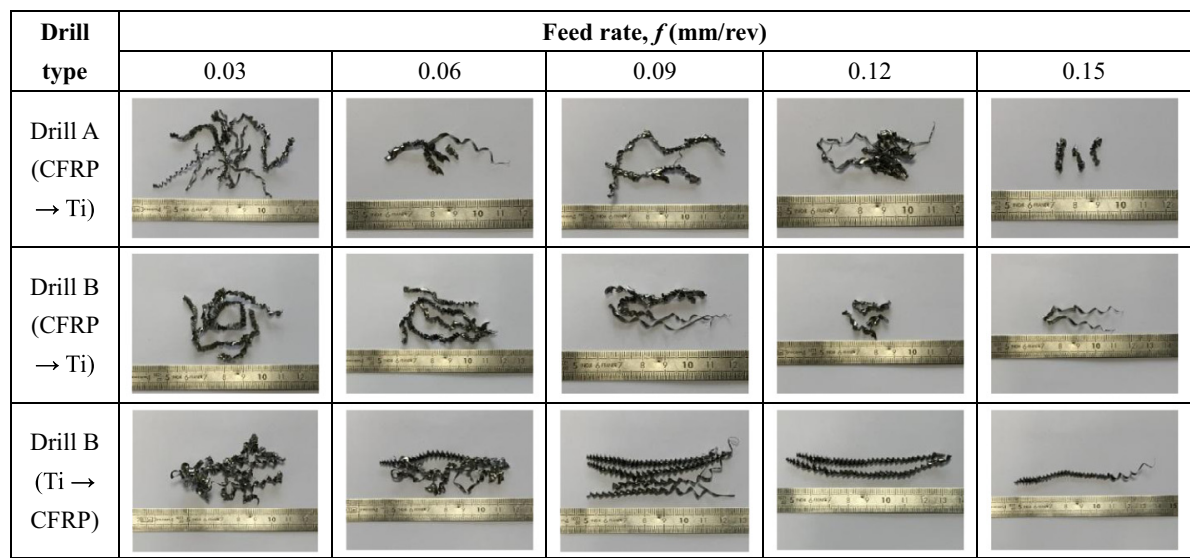

Fig. 15. Variation of the resected Ti chip shapes versus feed rate $(f)$ at a constant cutting speed of $15 \mathrm{~m} / \mathrm{min}$ while drilling hybrid CFRP/Ti stacks. 


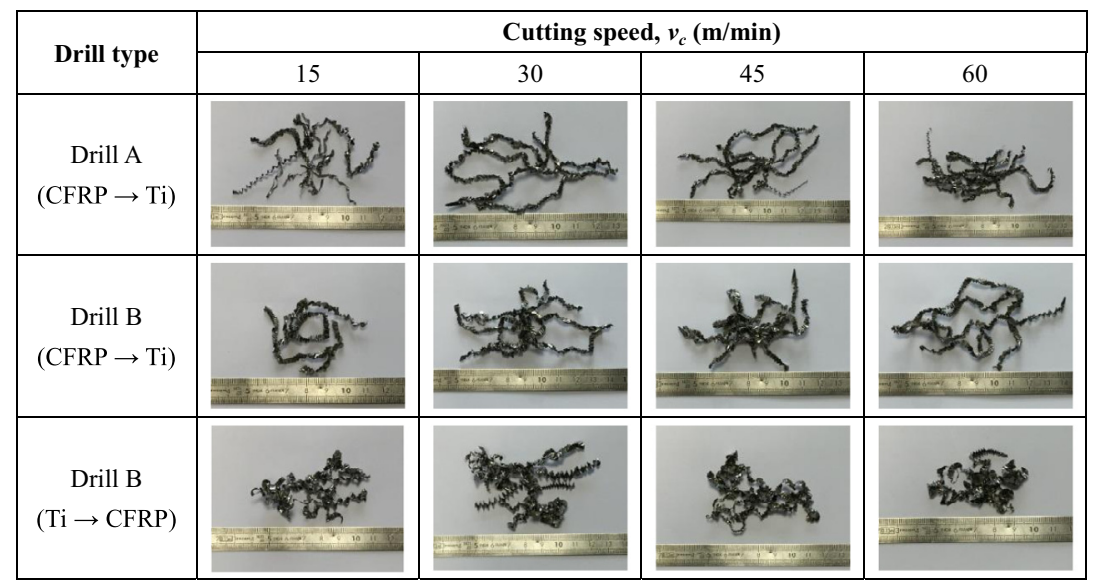

Fig. 16. Variation of the resected Ti chip shapes versus cutting speed $\left(v_{c}\right)$ at a constant feed rate of $0.03 \mathrm{~mm} / \mathrm{rev}$ while drilling hybrid CFRP/Ti stacks.

of spiral type. In the case of drill $\mathrm{B}$ in the CFRP $\rightarrow \mathrm{Ti}$ cutting sequence, both long to short spiral and ribbon chips are produced, whereas for drill $\mathrm{B}$ in the $\mathrm{Ti} \rightarrow \mathrm{CFRP}$ cutting sequence, they are primarily uniform spiral type with long ribbon features. Besides, it is again identified that with an increase in feed rate, the Ti chips are separated into small segments after drilling, indicating the improved chip breakability and easier chip evacuation. The activated mechanisms can be attributed to the increased chip crosssectional area (improved stiffness of the chip layer) when $f$ is elevated. The similar observations are also reported by Pawar et al. [8] for aluminum chip formation when drilling GLARE fiber metal laminates with different geometrical carbide drill bits. By contrast, the effects of cutting speed on chip breakability are marginal and the Ti chips basically remain the same length and type regardless of the varied cutting speed as shown in Fig. 16.

\subsection{Hole quality analysis}

In hybrid composite stack drilling, hole quality including machined surface roughness, hole size and geometrical accuracy is often a critical concern to ensure a tight stack assembly. For machined CFRP/Ti surface, the maximum $R_{a}$ values (arithmetic mean roughness) of $3.2 \mu \mathrm{m}$ and $1.6 \mu \mathrm{m}$ are usually required for CFRP phase and Ti phase, respectively [1]. For drilled CFRP hole size, a diameter tolerance less than $30 \mu \mathrm{m}$ is often demanded [18]. Previous studies $[11,12,21]$ have shown that the hole quality is greatly affected by input cutting variables (cutting speed and feed rate) when drilling hybrid composite stacks. In the following subsections, a comparative investigation on drilled surface roughness, hole diameter and roundness error was performed with respect to the used cutting parameters and implemented cutting sequence strategies.

\subsubsection{Surface roughness}

Figs. 17-19 show the most-used $R_{a}, R_{q}$, and $R_{z}$ parameters versus cutting speed and feed rate after drilling hybrid CFRP/Ti stacks. All the surface roughness measurements were made on the two individual materials (CFRP phase and Ti phase). As depicted in these figures, the $R_{a}$ values measured in the CFRP phase for drill A and drill $\mathrm{B}$ in the CFRP $\rightarrow$ Ti cutting sequence are partly lower than the required $R_{a}$ criterion of $3.2 \mu \mathrm{m}$ particularly when low feed rates are applied. However, for drill $\mathrm{B}$ in the $\mathrm{Ti} \rightarrow$ CFRP cutting sequence, the drilled CFRP surface finish completely meets the $R_{a}$ requirement. For $R_{a}$ values of the machined Ti phase, they are totally controlled below the criterion value of $1.6 \mu \mathrm{m}$ for all examined drill bits and cutting parameters. Besides, the surface roughness values of the machined Ti phase $\left(R_{a} \in[0.5111 \mu \mathrm{m}, 1.073 \mu \mathrm{m}]\right.$ for drill $\mathrm{A}$,
$R_{a} \in[0.373 \mu \mathrm{m}, 1.301 \mu \mathrm{m}]$ for drill B) are much lower than those measured in the CFRP phase $\left(R_{a} \in[2.016 \mu \mathrm{m}, 5.100 \mu \mathrm{m}]\right.$ for drill $\mathrm{A}, R_{a} \in[1.146 \mu \mathrm{m}, 4.919 \mu \mathrm{m}]$ for drill B) when operated in the identical CFRP $\rightarrow$ Ti cutting sequence. On the contrary, for Ti $\rightarrow$ CFRP cutting sequence, the $R_{a}$ values of the CFRP phase are obtained within the range of $0.4-2.0 \mu \mathrm{m}$, showing the comparable magnitudes to those of the machined $\mathrm{Ti}$ phase $\left(R_{a} \in[0.279 \mu \mathrm{m}\right.$, $1.331 \mu \mathrm{m}])$. In addition, the measured CFRP surface roughness parameters in the $\mathrm{Ti} \rightarrow$ CFRP cutting sequence are entirely lower than those gained in the CFRP $\rightarrow$ Ti cutting sequence with the same drill $\mathrm{B}$. The phenomena indicate that the Ti $\rightarrow$ CFRP drilling favors the improvement of the drilled hole surface finish. Since for each drilling sequence, the identical fresh drill bit was used, the primary cause due to the different influences of tool wear on drilled surface finish could be negligible. Therefore, one reasonable explanation should be that the Ti chip evacuation indeed has a remarkable influence on the machined CFRP surface. This is because when drilling from Ti phase to CFRP phase, the resected spiral Ti chips can be firstly transported from the top drilled Ti holes without any damage on the bottom CFRP hole surface. In contrast, when drilling from CFRP $\rightarrow \mathrm{Ti}$, the sharp and hot Ti chips produced in the bottom Ti phase will cause serious abrasion effects on the relatively brittle CFRP hole wall surfaces during their long-time evacuation, and hence will greatly deteriorate the CFRP hole quality and give rise to the increased surface roughness. Besides, the $R_{a}$ values produced by the TiAlN-coated drill $B$ are found to be slightly lower than those generated by the uncoated drill A when performed under the identical cutting conditions. The reason can be attributed to the superior mechanical/physical properties of the TiAlN coating against the severe friction of the tool-chip interaction during the drilling operation. Moreover, the feed rate is confirmed to have a remarkable influence on the drilled hole surface roughness for all tested trials, where increasing $f$ greatly increases the surface roughness parameters. For instance, the maximum values of $R_{a}$, $R_{q}$, and $R_{z}$ are usually measured on holes drilled under highest feed-rate conditions (e.g., test Nos. 5, 10, 15 and 20 as shown in Figs. 17-19). In contrast, the effect of cutting speed on surface roughness is obscure and insignificant. Additionally, the comparative results in Figs. 17-19 also show that for achieving better surface finish (i.e., lower surface roughness), the $\mathrm{Ti} \rightarrow$ CFRP cutting sequence as well as the combination of low feed rate and moderate cutting speed should be adopted when drilling hybrid CFRP/Ti stacks.

\subsubsection{Hole diameter and roundness error}

In hybrid CFRP/Ti stack drilling, the disparate thermal expansion coefficients between stacked composite laminate and metal 

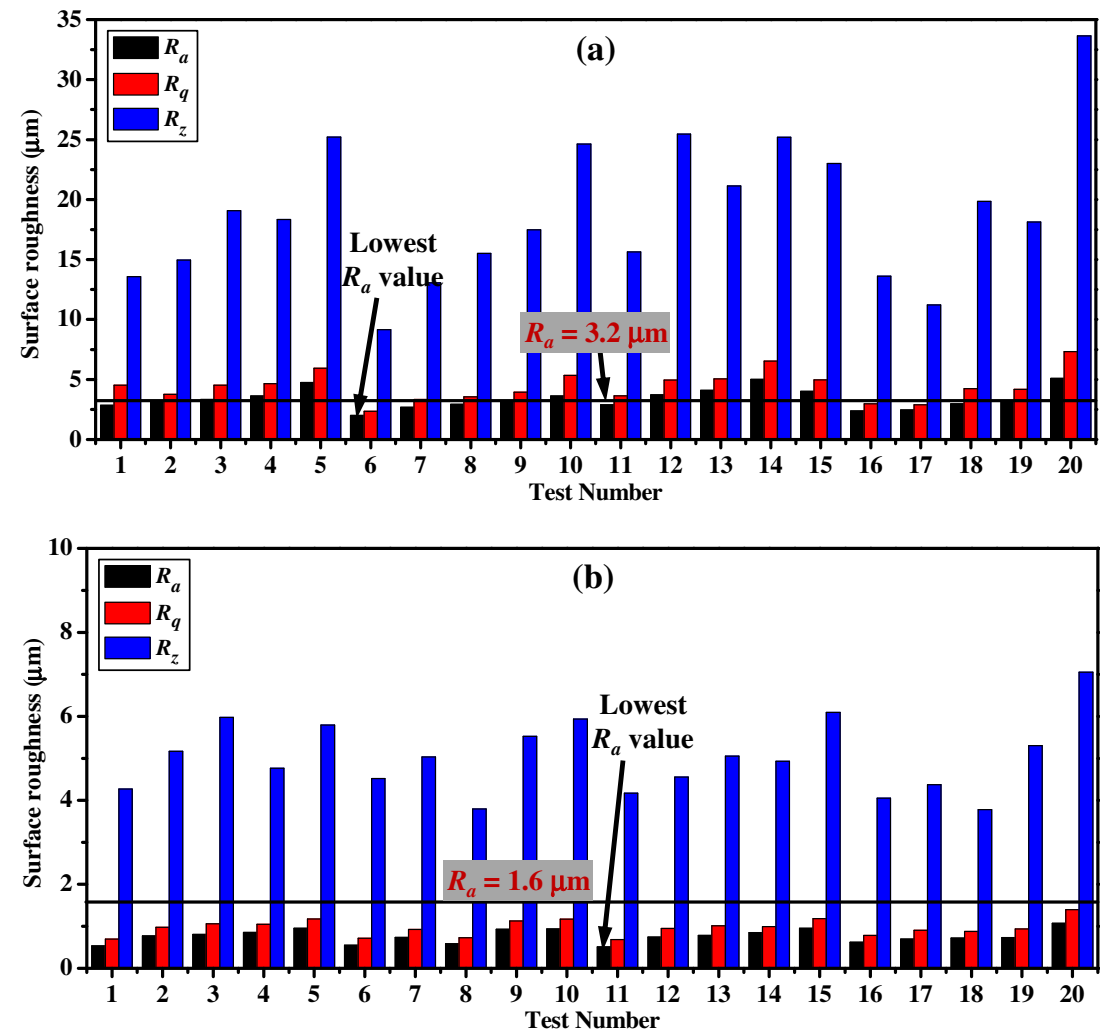

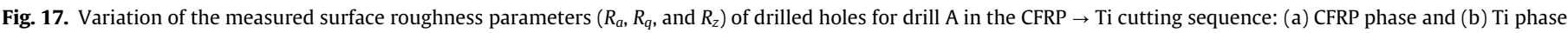
(cutting conditions for test Nos. 1-20 can be found in Table 4).
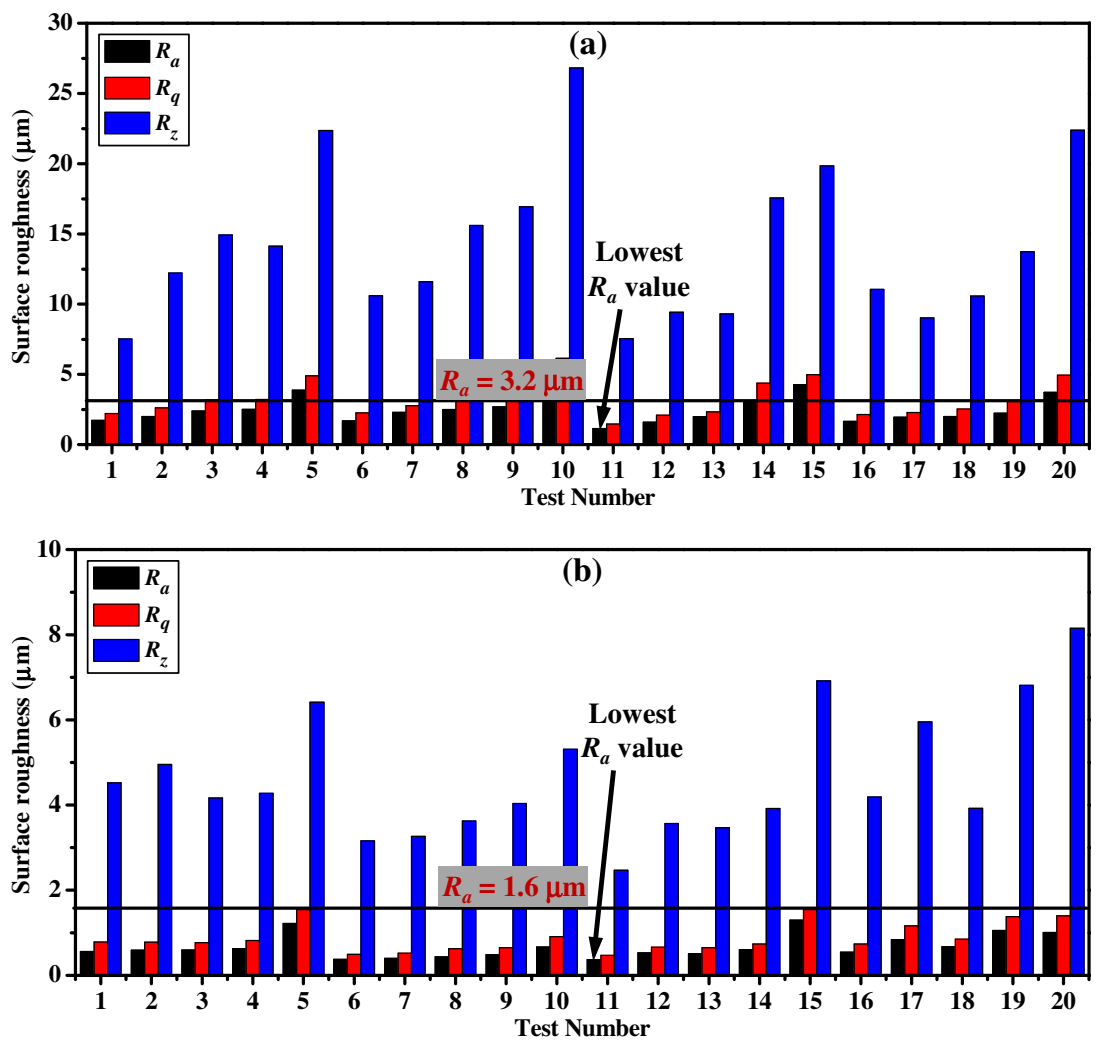

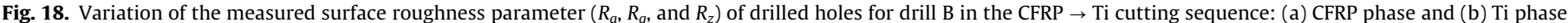
(cutting conditions for test Nos. 1-20 can be found in Table 4). 

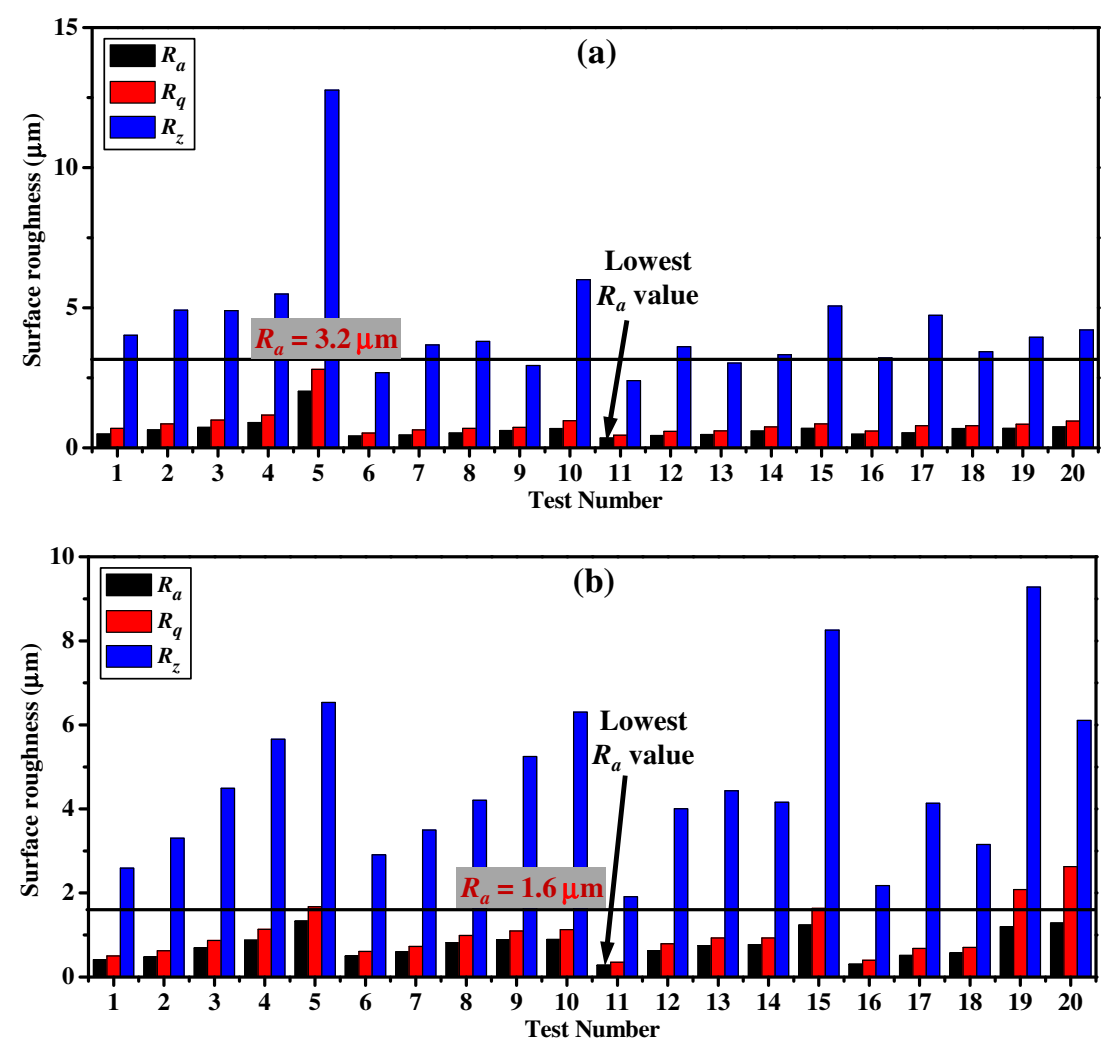

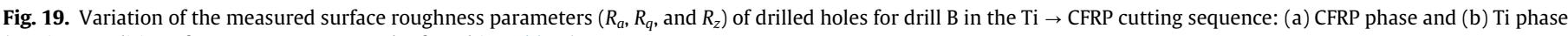
(cutting conditions for test Nos. 1-20 can be found in Table 4).

(a)

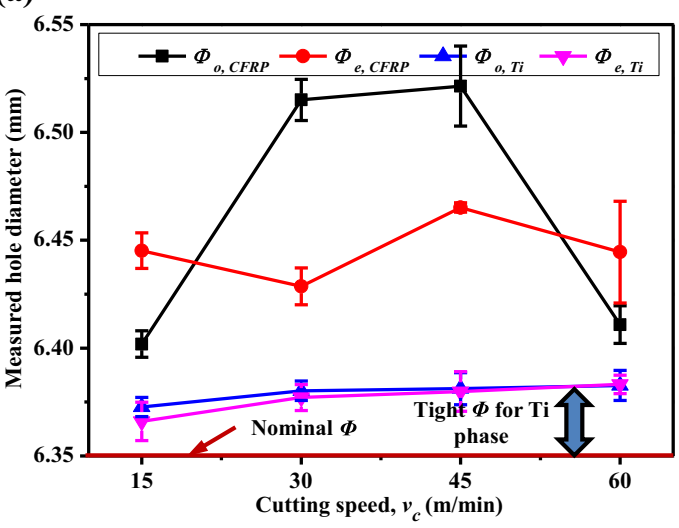

(b)

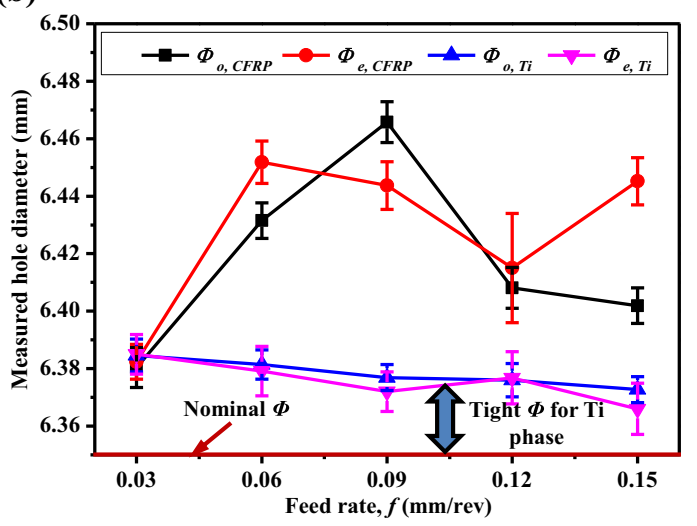

Fig. 20. Effects of (a) cutting speed $\left(v_{c}\right)(f=0.15 \mathrm{~mm} / \mathrm{rev})$ and (b) feed rate $(f)\left(v_{c}=15 \mathrm{~m} / \mathrm{min}\right)$ on drilled hole diameters for drill A in the CFRP $\rightarrow$ Ti cutting sequence.

alloy make it more difficult to produce consistent hole size. Therefore, the hole diameter and roundness error measurements were made on each individual layer as discussed in Section 2.5.

Figs. 20-22 show the evolution of various measured hole diameters ( $\Phi_{o, \text { CFRP }}, \Phi_{e, \text { CFRP }}, \Phi_{o, T i}$ and $\left.\Phi_{e, T i}\right)$ for each stacked phase versus the utilized cutting conditions. Firstly, it is clear that both cutting speed and feed rate have a significant influence on the drilled hole diameters. For CFRP $\rightarrow$ Ti cutting sequence as depicted in Figs. 20 and 21 , the produced hole size in either CFRP phase or Ti phase is totally oversized (larger than $\Phi_{\text {nom }}=6.35 \mathrm{~mm}$ ), irrespective of the used drill bits. By contrast, the hole diameters produced in the $\mathrm{Ti} \rightarrow$ CFRP cutting sequence are partly oversized and partly undersized, greatly dependent on the used cutting parameters (Ref. Fig. 22). Besides, the Ti $\rightarrow$ CFRP cutting sequence is found to produce more consistent CFRP and Ti hole diameters close to the nominal drill diameter $\left(\Phi_{\text {nom }}\right.$ ) of $6.35 \mathrm{~mm}$ than those obtained in the CFRP $\rightarrow$ Ti drilling sequence as shown in Fig. 22. The predominant factor for the latter (hole diameters in CFRP $\rightarrow$ Ti drilling) should be attributed to the intense influences of Ti chip evacuation on the hole wall circumferences. This is because when drilling is operated in the CFRP $\rightarrow$ Ti cutting sequence, the resected sharp and hot Ti chips should cause detrimental abrasions on the drilled CFRP hole wall circumferences, and hence will enlarge their original hole circles during the evacuation process. By contrast, the $\mathrm{Ti} \rightarrow$ CFRP cutting sequence prevents the drilled CFRP holes from serious erosions of the Ti chip ejection, thus producing more consistent hole diameters.

Moreover, from the aspect of achieving consistent hole size, the TiAlN-coated drill B is found to yield a better performance than its counterpart one (uncoated drill A) under the identical CFRP $\rightarrow \mathrm{Ti}$ 
(a)

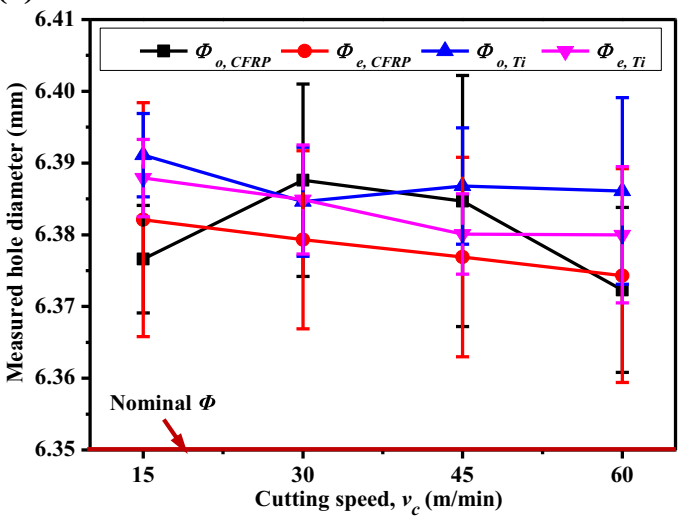

(b)

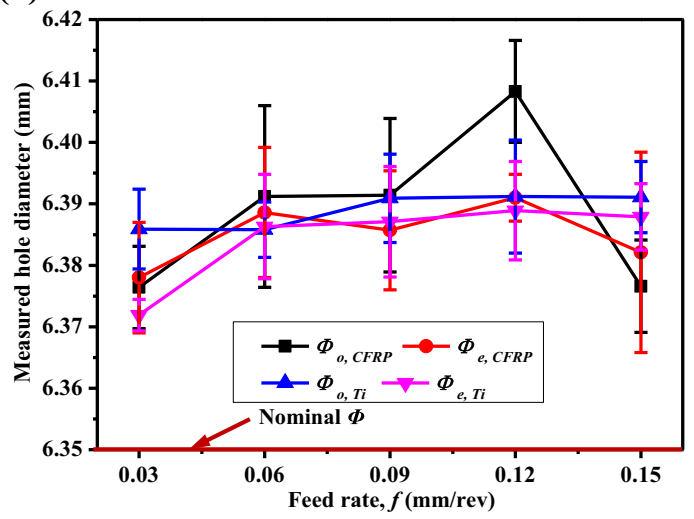

Fig. 21. Effects of (a) cutting speed $\left(v_{c}\right)(f=0.15 \mathrm{~mm} / \mathrm{rev})$ and (b) feed rate $(f)\left(v_{c}=15 \mathrm{~m} / \mathrm{min}\right)$ on drilled hole diameters for drill B in the CFRP $\rightarrow$ Ti cutting sequence.

(a)

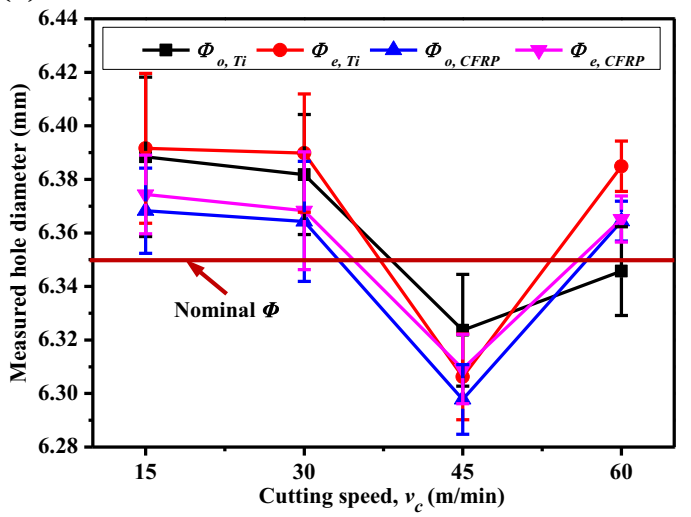

(b)

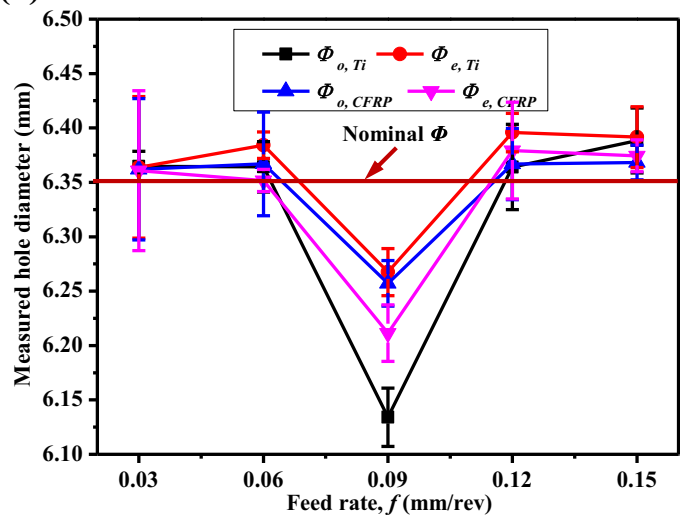

Fig. 22. Effects of (a) cutting speed $\left(v_{c}\right)(f=0.15 \mathrm{~mm} / \mathrm{rev})$ and (b) feed rate $(f)\left(v_{c}=15 \mathrm{~m} / \mathrm{min}\right)$ on drilled hole diameters for drill B in the Ti $\rightarrow$ CFRP cutting sequence.

cutting sequence. The reason may be due to the superior behaviors of the TiAlN coating in maintaining sharp cutting edges and excellent wear resistance for either CFRP phase hole making or Ti phase hole making. As for drill $\mathrm{A}$ in the CFRP $\rightarrow$ Ti cutting sequence, a large disparity in hole diameters of CFRP phase and $\mathrm{Ti}$ phase is identified (Ref. Fig. 20). The $\Phi_{T i}$ commonly exhibits a much smaller value (much closer to $\Phi_{\text {nom }}$ ) than that of $\Phi_{\text {CFRP }}$ due to the different TECs and elastic moduli of the Ti phase and CFRP phase. In addition, based on the acquired results in Figs. 20-22, it can be concluded that for generating tight hole diameters, the $\mathrm{Ti} \rightarrow$ CFRP cutting sequence, low feed rate and low cutting speed should be adopted when drilling hybrid CFRP/Ti stacks.

Additionally, the parametric effects on hole roundness error of CFRP phase and Ti phase when using different drill bits and cutting sequences are also shown in Figs. 23 and 24, respectively. As depicted in these figures, when low feed rate is applied (e.g., $f=0.03 \mathrm{~mm} / \mathrm{rev}$ ), the roundness error in either CFRP hole or Ti hole is found to be around $5-10 \mu \mathrm{m}$. With the increase of feed rate, the roundness error is observed to firstly experience a quick evolution and finally reach its maximum value at $f=0.15 \mathrm{~mm} / \mathrm{rev}$. Besides, the cutting speed is found to have a great influence on the measured roundness error. However, its evolution law versus roundness error is not fully clear. In some cases, the cutting speed exhibits a positive impact on the roundness error (e.g., drill B in CFRP $\rightarrow$ Ti cutting sequence in Fig. 24(b)), whereas for other cases, it shows a totally negative impact (e.g., drill B in Ti $\rightarrow$ CFRP cutting sequence in Fig. 24(b)). In summary, to minimize hole roundness error, typically a parametric combination of low feed rate and low cutting speed should be utilized for hybrid CFRP/Ti stack drilling.

\subsection{Hole damage study}

When drilling hybrid CFRP/Ti stacks, the cutting-induced damage comprises both polymeric defects (e.g., matrix cratering, delamination, fiber pullout, and thermal alteration) and metallic imperfections (e.g., hole size error, position error, and burrs). Among them, the delamination damage promoted in the CFRP phase and the burr defect produced in the Ti phase are usually the key problems for the assembly of the bi-material system. To investigate the hole damage extent, the drilled hole edge morphology is firstly inspected. Afterward, the delamination damage and burr defect are analyzed.

\subsubsection{Hole edge morphology}

Fig. 25 shows the recorded hole edge morphologies of the drilled CFRP phase versus cutting speed $\left(v_{c}\right)$ and feed rate $(f)$ when using drill B in the CFRP $\rightarrow$ Ti cutting sequence. It is noticeable that the feed rate exhibits a great influence on the machined hole edge quality. When drilling is operated at a low feed rate (e.g., $f=0.03 \mathrm{~mm} / \mathrm{rev}$ ), nearly a smooth hole edge is achieved as depicted in Fig. 25(c). With the increase of $f$, a large area of damaged zone is produced around the hole edge circumference, especially when $f$ reaches its maximum value of $0.15 \mathrm{~mm} / \mathrm{rev}$. By contrast, the effect of cutting speed $\left(v_{c}\right)$ on the hole edge damage extent is not so significant as shown in Fig. 25(b). In the following Sections 3.5.2 and 
(a)

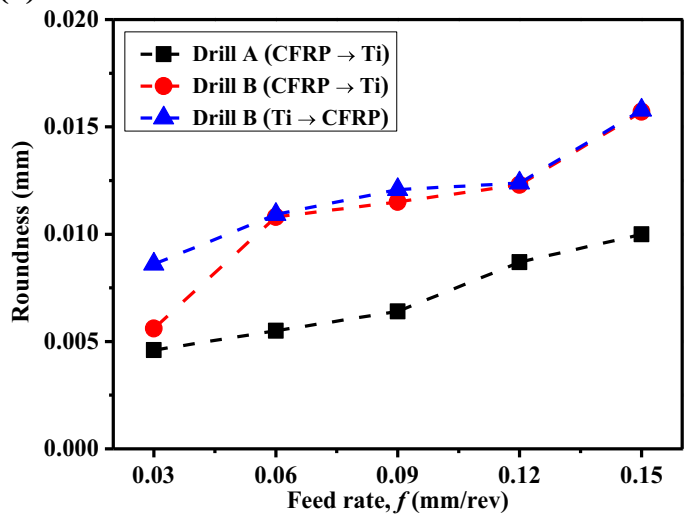

(b)

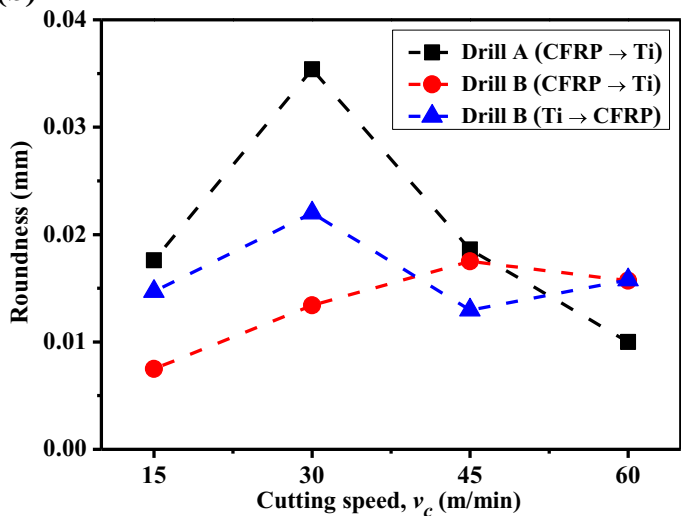

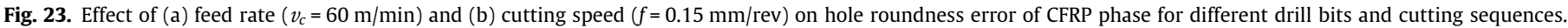

(a)

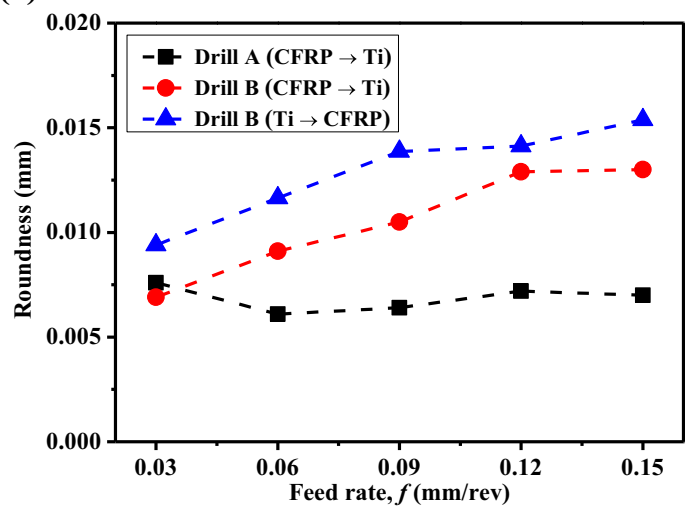

(b)

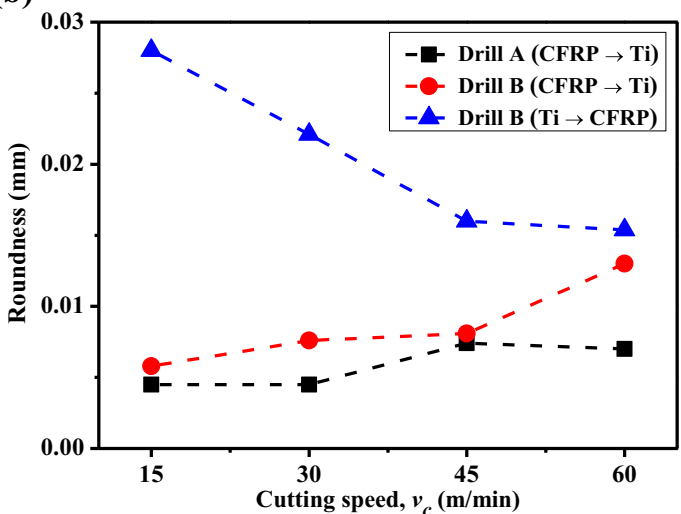

Fig. 24. Effect of (a) feed rate $\left(v_{c}=60 \mathrm{~m} / \mathrm{min}\right)$ and (b) cutting speed $(f=0.15 \mathrm{~mm} / \mathrm{rev})$ on hole roundness error of Ti phase for different drill bits and cutting sequences.

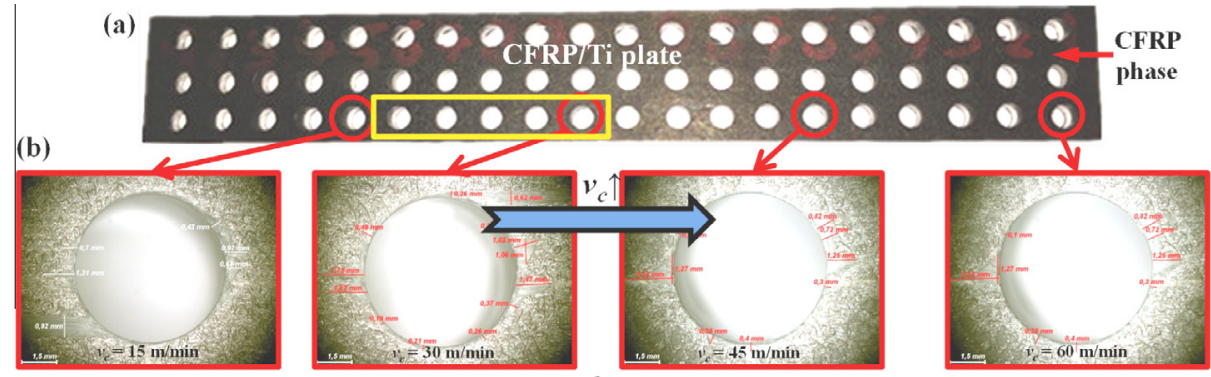

(c)
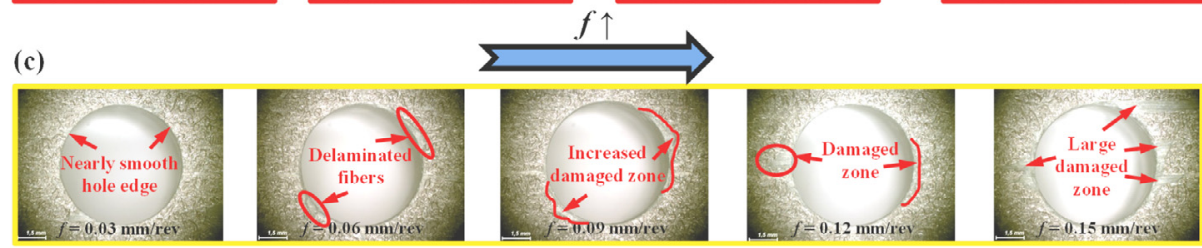

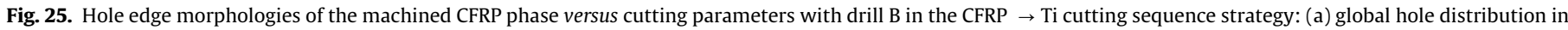
the CFRP/Ti plate, (b) $f=0.15 \mathrm{~mm} / \mathrm{rev}$, and (c) $v_{c}=30 \mathrm{~m} / \mathrm{min}$.

3.5.3, several quantitative analyses are conducted to clarify the actual parametric influences on the drilling-induced hole damage in terms of delamination damage and burr defect.

Moreover, Figs. 26 and 27 also present the comparative hole edge morphologies of both CFRP phase and Ti phase after drilling with different drill bits and cutting sequences. Apart from the significantly positive impact of $f$ on the hole edge morphology, the CFRP $\rightarrow$ Ti cutting sequence commonly produces more accurate CFRP hole shapes and lower fiber/matrix damage as compared to the $\mathrm{Ti} \rightarrow$ CFRP cutting sequence as depicted in Fig. 26. The key cause can be attributed to the supporting role of the bottom $\mathrm{Ti}$ phase in preventing laminate deflection and limiting the workpiece 


\begin{tabular}{|c|c|c|c|c|c|}
\hline \multirow{2}{*}{$\begin{array}{l}\text { Drill } \\
\text { type }\end{array}$} & \multicolumn{5}{|c|}{ Feed rate, $f(\mathrm{~mm} / \mathrm{rev})$} \\
\hline & 0.03 & 0.06 & 0.09 & 0.12 & 0.15 \\
\hline \multicolumn{6}{|c|}{ Drill A } \\
\hline \multicolumn{6}{|l|}{ (CFRP } \\
\hline \multicolumn{6}{|l|}{ Drill B } \\
\hline \multicolumn{6}{|l|}{ (CFRP } \\
\hline \multicolumn{6}{|l|}{$\rightarrow \mathrm{Ti})$} \\
\hline Drill B & & & & & \\
\hline$(\mathrm{Ti} \rightarrow$ & & & & & \\
\hline CFRP) & & & & & \\
\hline
\end{tabular}

Fig. 26. Comparative hole edge sides of the drilled CFRP phase for different drill bits and cutting sequence strategies $(\times 20)$.

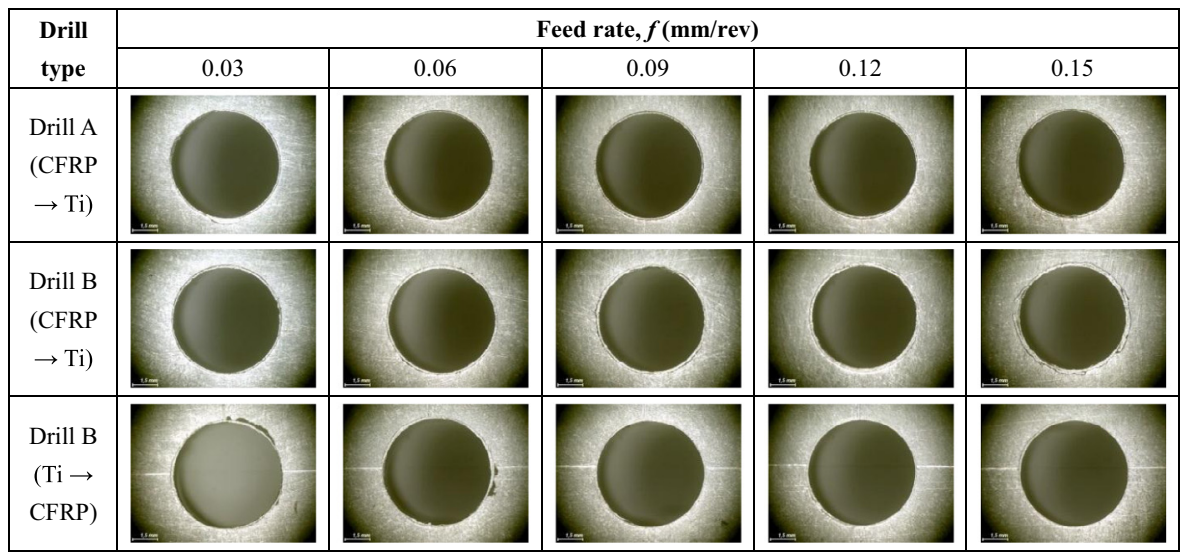

Fig. 27. Comparative hole edge sides of the drilled Ti phase for different drill bits and cutting sequence strategies $(\times 20)$.

dynamics when drilling from CFRP phase to Ti phase. Besides, the uncoated drill $\mathrm{A}$ is found to produce a little bit higher quality of hole exit edge than that of drill $\mathrm{B}$ under the identical cutting sequence and cutting parameters. For drilled Ti hole edge, the feed rate is identified to have a remarkable effect on the exit burr formation. However, the influences of different drill bits and cutting sequences on drilled $\mathrm{Ti}$ hole edges are not fully apparent.

\subsubsection{Delamination damage analysis}

In hybrid CFRP/Ti stack drilling, the delamination occurring in the composite phase is often a most critical failure mode due to its irreparable nature, which accounts for a large number of part rejections in the real production. To assess its damage extent, the most-used one-dimensional delamination factor $\left(F_{d}\right)$ based on the maximum diameter was adopted in this work. The $F_{d}$ is defined as the ratio of the maximum diameter $\left(D_{\max }\right)$ of the delamination area to the nominal hole diameter $\left(D_{\text {nom }}\right)$, as given by Eq. (5) $[28,29]$.

$F_{d}=\frac{D_{\max }}{D_{\text {nom }}}$

Figs. 28-30 show the parametric effects on drilling-induced delamination extent with respect to different drill bits and cutting sequences. It is noticeable that the feed rate plays a predominant role in affecting the drilling-induced delamination in such manner that a small increase of $f$ usually promotes greatly elevated $F_{d}$, regardless of the used drill bits or cutting sequences. Besides, the cutting speed $\left(v_{c}\right)$ approximately shows a negative impact on the evolution of $F_{d}$ especially for drill A and drill B when operated in the CFRP $\rightarrow$ Ti cutting sequence. However, for Ti $\rightarrow$ CFRP drilling, the impact of $v_{c}$ on $F_{d}$ is found to be generally positive.

Moreover, Fig. 31 also shows the comparative $F_{d}$ results when drilling hybrid CFRP/Ti stacks with respect to different drill bits and cutting sequences. The results further confirm the significantly positive impact of $f$ on $F_{d}$. Also, it is clear that the CFRP $\rightarrow$ Ti drilling globally induces a lower delamination extent than that of $\mathrm{Ti} \rightarrow$ CFRP drilling, except two abnormal drilling results (test No. 5: $v_{c}$ $=15 \mathrm{~m} / \mathrm{min}, f=0.15 \mathrm{~mm} / \mathrm{rev}$, and test No. $10: v_{c}=30 \mathrm{~m} / \mathrm{min}, f=$ $0.15 \mathrm{~mm} / \mathrm{rev}$ ) in Fig. 31. The activated mechanisms as addressed earlier should be owing to the supporting effects of the bottom Ti alloy on increasing the stiffness of the exit CFRP hole layer while drilling. In addition, such findings also agree with the predictions of the analytical models proposed by Qi et al. [13] for modeling delamination-free drilling of $\mathrm{FRP} /$ metal stacks. Furthermore, through the comparisons between drill $\mathrm{A}$ and drill $\mathrm{B}$, it can be inferred that the uncoated drill A generates a lower delamination extent than its counterpart one. The reason can be attributed to the availability of the superior geometrical features (e.g., small chisel edge length, low point angle and helix angle) that promote lower thrust force than drill B (as discussed in Section 3.2). As such, a lower delamination factor $\left(F_{d}\right)$ is obtained. Overall, to minimize the delamination damage, the CFRP $\rightarrow$ Ti drilling together with drill A should be adopted when drilling hybrid CFRP/Ti stacks.

\subsubsection{Burr defect analysis}

To ensure a tight CFRP/Ti assembly, the burr defect produced in the Ti phase is often a key problem as compared to other metallic 


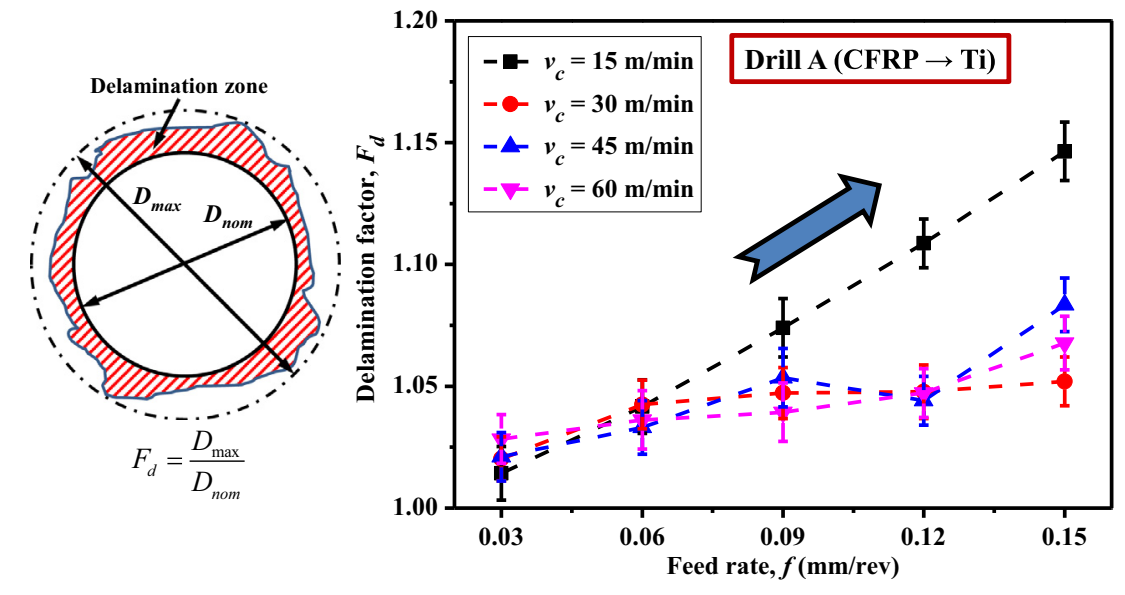

Fig. 28. Parametric effects on delamination factor $\left(F_{d}\right)$ when using drill A (CFRP $\rightarrow$ Ti cutting sequence).
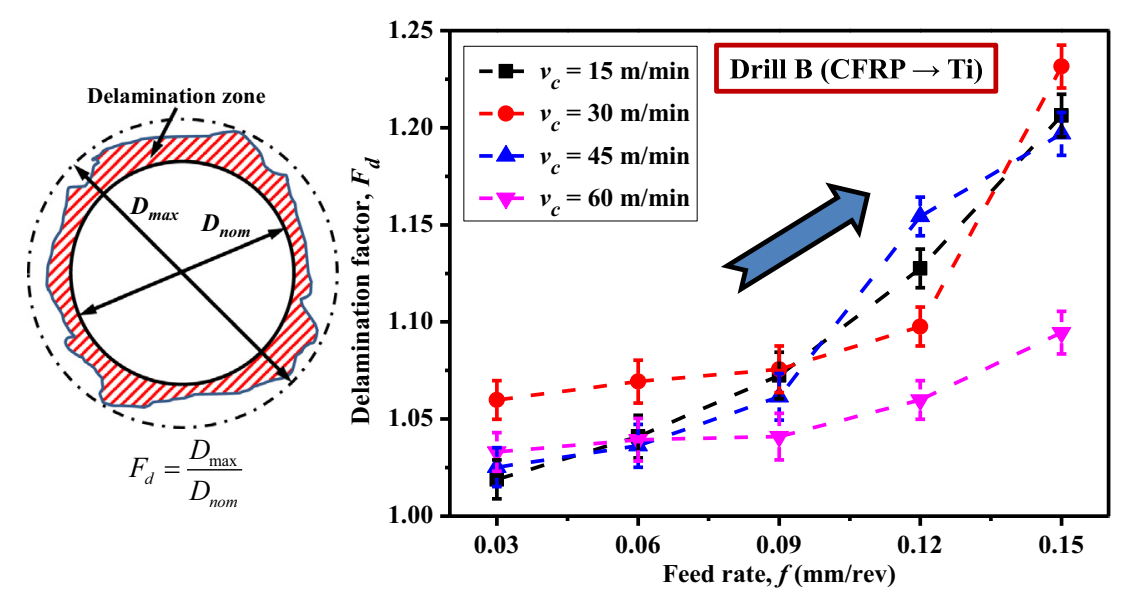

Fig. 29. Parametric effects on delamination factor $\left(F_{d}\right)$ when using drill B (CFRP $\rightarrow$ Ti cutting sequence).
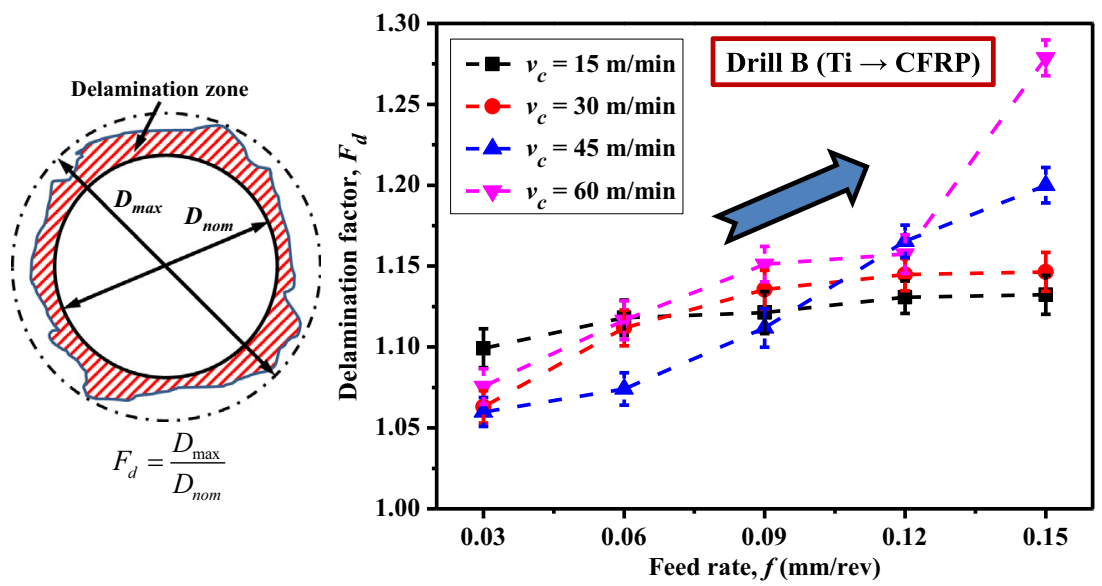

Fig. 30. Parametric effects on delamination factor $\left(F_{d}\right)$ when using drill B (Ti $\rightarrow$ CFRP cutting sequence).

surface damage since it usually leads to further disassembly, deburring and re-assembly of the stacks. The drilling-induced burr formation is often highly dependent on the input cutting parameters and can be thoroughly tracked back to the tool engagement time, thrust force and frictional heat generation [9,11].

Figs. 32-34 show the effects of cutting speed and feed rate on burr width when drilling hybrid CFRP/Ti stacks with respect to different drill bits and cutting sequences. It can be seen that the variation law of burr width promoted by drill A in CFRP $\rightarrow$ Ti cutting sequence (Ref. Fig. 32) versus feed rate $(f)$ is not fully clear, in which the minimum and maximum burr widths are nearly similar and close to each other. By contrast, the impact of $f$ on burr width for drill B is totally positive or negative, greatly dependent on the used cutting sequence strategies. For the observation in Fig. 34, an increased feed rate normally decreases the induced burr extent, which agrees well with the observation of Ramulu et al. [9] 


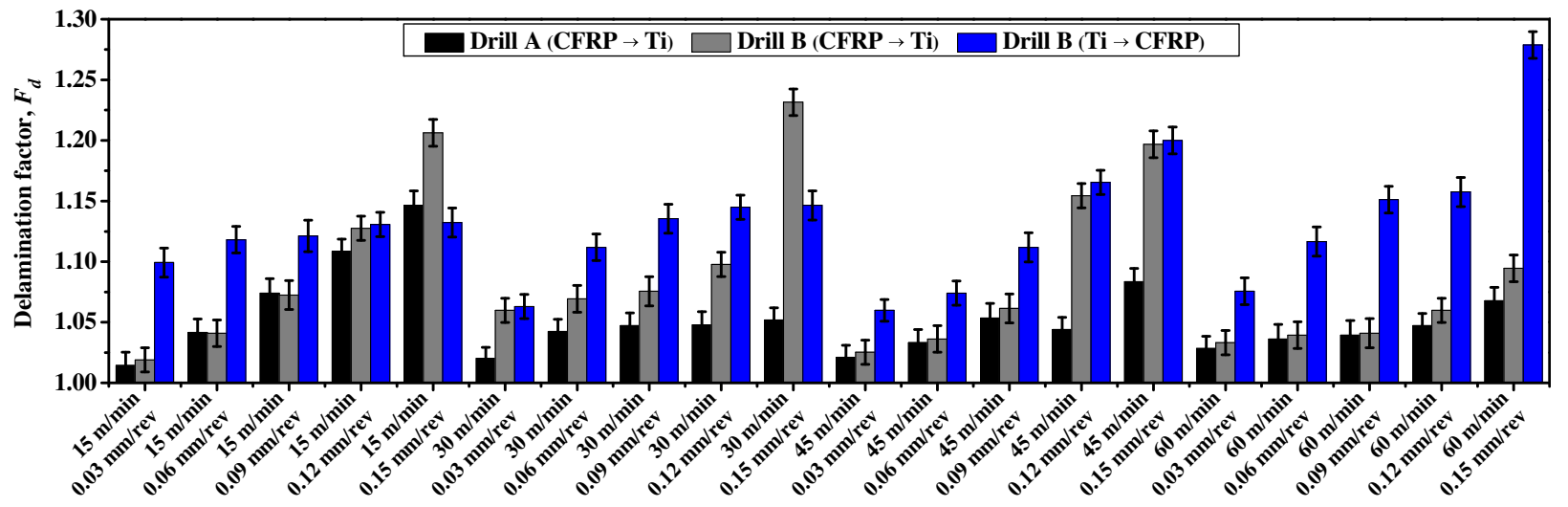

Fig. 31. Comparative results of delamination factor $\left(F_{d}\right)$ with respect to different drill bits and cutting sequence strategies.

when drilling hybrid ( $\mathrm{Gr} / \mathrm{Bi}) / \mathrm{Ti}$ stacks. Moreover, the impact of cutting speed on the induced burr extent is generally positive, i.e., an increased $v_{c}$ often gives rise to the elevated burr width formation. The reason can be attributed to the softening effects of the highly generated frictional heat on surrounding work material when $v_{c}$ is elevated, which greatly degrades the stiffness of the exit Ti layer and makes it more difficult for cutting off.

Further, the comparative burr width results in Fig. 35 also reveal that the drill $\mathrm{B}$ operated in the CFRP $\rightarrow$ Ti cutting sequence normally promotes higher burr widths than its counterpart one, especially under high cutting-speed conditions. In contrast, the drill A globally shows the best performance, with which the lowest burr width can be obtained under the low feed-rate conditions. Moreover, from the aspect of minimizing burr defect formation, the $\mathrm{Ti} \rightarrow$ CFRP drilling produces a lower defect extent when high feed rates are applied as compared to the CFRP $\rightarrow$ Ti drilling. The reason can be due to the supporting role of the bottom CFRP phase in increasing the stiffness of the exit Ti layer, thus facilitating the reduction of the exit Ti burr defect.

\subsection{Drill design implications}

In manufacturing processes, tool material composition and tool geometrical feature are two important factors that greatly influence the on-site cutting-induced phenomena including force generation, heat transfer, subsurface damage, and tool wear. The functionality of drill geometrical feature affects the cutting phenomena primarily via its influences on chip separation mode. By

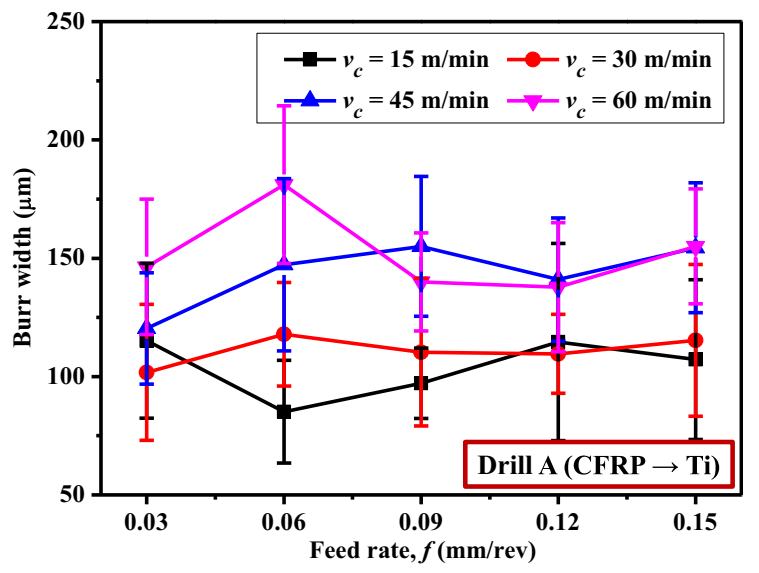

Fig. 32. Parametric effects on burr width when using drill A (CFRP $\rightarrow$ Ti cutting sequence).

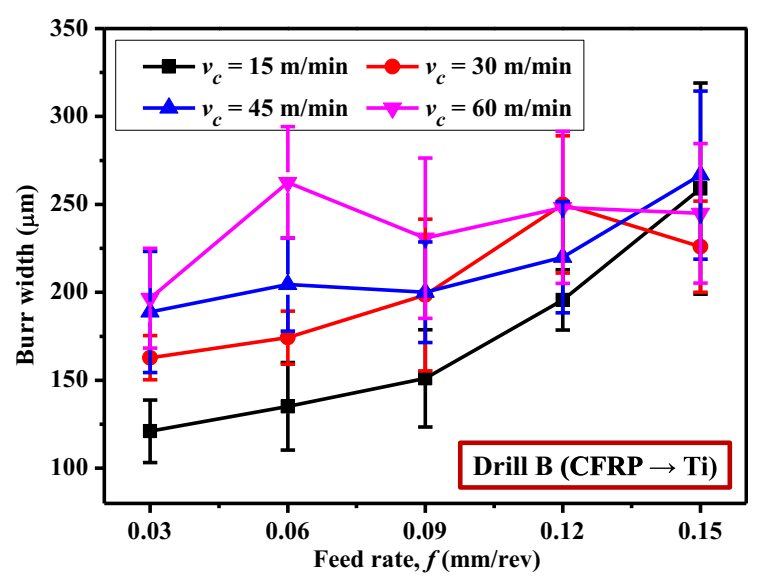

Fig. 33. Parametric effects on burr width when using drill B (CFRP $\rightarrow$ Ti cutting sequence).

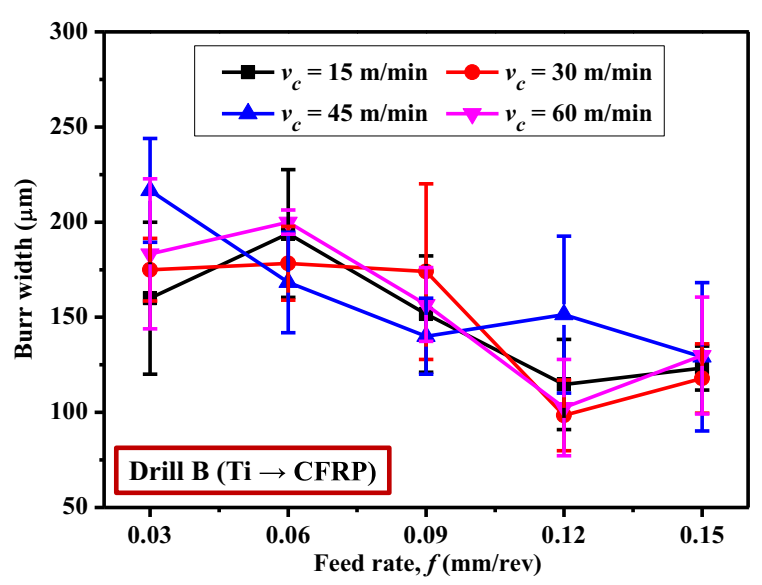

Fig. 34. Parametric effects on burr width when using drill B (Ti $\rightarrow$ CFRP cutting sequence).

contrast, the tool material composition mainly aims at altering the tool-chip frictional coefficient and tool wear behavior. In such case, when two types of twist drills differing in geometrical feature and material composition are employed, the observed disparate tool performances should be thoroughly tracked back to the competition between the influences of tool geometry and tool material on drilling responses. That's to say, the drill performance depends 


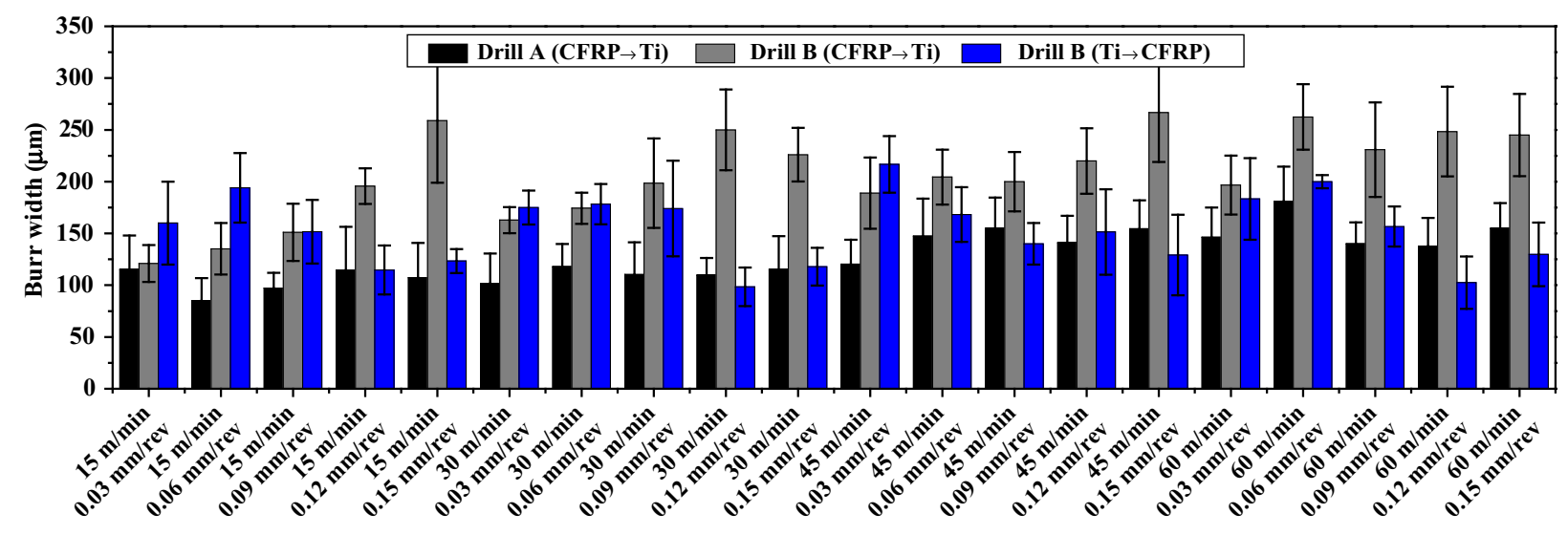

Fig. 35. Comparative results of burr width with respect to different drill bits and cutting sequence strategies.

significantly on which factor acts as a predominant role in affecting the drilling-induced phenomena.

Regarding the used conventional twist drill, it is well known that the drill rake angle decreases toward the drill center (drill tip) and approaches large negative values in the chisel edge zone. Thus, while the outer edge produces a smooth chip, the inner does not. The material under the chisel edge is subjected to severe extrusion deformation by large displacements instead of shearing cutting. In addition, the chisel edge is also assumed to contribute approximately $50-60 \%$ of the total thrust force generation $\left(F_{z}\right)$. As such, the drill bit A which has a short chisel edge length should promote a lower $F_{z}$ magnitude since the chisel edge acts as a vital role as shown in Fig. 12. Besides, even though drill B has a protection of TiAlN coating, however, the coating probably induces negligible effects on reducing the tool-chip friction coefficient in order to decrease the thrust force as the coating often suffers severe peeling or micro chipping when drilling hybrid CFRP/Ti stacks. The experimental work done by Isbilir and Ghassemieh [12] has shown that when applying TiAlN coating in drilling hybrid CFRP/ Ti6Al4V stacks, the drill edges underwent intense flank/crater wear and serious coating peeling even after drilling quite a few number of holes ( 15 holes). Therefore, it could be deduced that in current drilling cases, the benefits of TiAlN coating on improving the machinability of the hybrid CFRP/Ti stack would be minor. With regard to the torque component $(T)$, it is greatly influenced by drill point angle and helix angle since these two geometrical angles primarily affect the proportion of torque in the nominal force generation. As such, drill B with high point and helix angles was observed to promote lower torque magnitudes especially for $\mathrm{Ti}$ phase drilling as shown in Fig. 13.

For resected Ti chip type, both drill A and drill B were found to produce the similar chip morphology especially from a macroscale observation as depicted in Figs. 15 and 16. However, one point should be emphasized that from the aspect of chip ejection, twist drill with a higher helix angle often facilitates the chip evacuation due to the increased rake angle contributing to chip breakage. As such, the drill $B$ was found to promote easier chip ejection as compared to drill $\mathrm{A}$ throughout the drilling trials. With respect to the machined surface quality (surface roughness, hole diameter and roundness error), the differences between drill A and drill B were not so pronounced. However, for drilling-induced subsurface damage, drill A was found to globally outperform drill B in terms of delamination formation and burr width extent, which indicates a more significant influence of tool geometrical feature on CFRP/Ti drilling than tool material composition. For delamination damage, it is believed by many researchers [30-32] that thrust force is a key contributor responsible for its formation, i.e., a higher thrust force often leads to a larger delamination extent. In such circumstance, drill A with short chisel edge feature was confirmed to induce lower delamination damage (Ref. Fig. 31) due to the lower thrust force generation as elaborated earlier. Furthermore, the short chisel edge length for drill $A$ also facilitates the drill centering and improves the chip separation nearby the drill tip, thus decreasing the exit burr formation as shown in Fig. 35. The reduced chisel edge plays clearly herein an important role in drill centering. By contrast, drill B with long chisel edge characteristics promotes high thrust force, and hence induces higher extents of delamination damage and burr width (Ref. Fig. 35) even though the TiAlN coating may more or less bring some improvements on the harsh cutting conditions of hybrid CFRP/Ti drilling.

Therefore, through the above analyses, it can be deduced that when drilling hybrid CFRP/Ti stacks, tool geometrical feature plays a more significant role in affecting the final drilling responses than tool material composition. This means improving drill geometrical characteristics (chisel edge length, rake angle, point angle, helix angle, etc.) should be a more effective way to improve the machinability of the bi-material system. The experimental results also give the ideas to conclude some rules of the functional design of special drill bits when drilling hybrid CFRP/Ti stacks as summarized below. For decreasing thrust force, short or zero chisel edge length is preferred for a drill bit in order to minimize the drilling-induced delamination and strengthen the drill centering. For heat transfer, a high clearance angle often reduces frictional forces and hence heat generation. To decrease the temperature accumulation as well as wear at the outer cutting edges, the use of a double point angle in multifaceted drill design will be a possible means. Besides, for facilitating Ti chip ejection, i.e., reducing its influences on the secondary damage of the drilled composite holes, the geometrical design with high point angle and high helix angle should be adopted. Furthermore, with the recent advances in tooling technology, various types of specialized drill geometrical designs including K-land design [33], two-stage point design [34], and double cone design $[35,36]$ have been successfully applied in drilling hybrid composite stacks, and have been demonstrated to achieve improved hole quality and increased tool life as compared to conventionally designed twist drills. Nevertheless, there is no functional drilling tool for drilling CFRP/Ti material in existence. A new design of special drill bits for drilling CFRP/Ti stacks as function of cutting sequence strategy could be suggested. The socalled Multifaceted Drill (MFD) with functional design can indeed be conceived. The functional design of such MFD aims at:

- Speeding up heat transfer and chip ejection: Since the thermal conductivities of both CFRP and Ti are very low, the point angle must be relatively larger to reduce the temperature of the periphery and to facilitate the chip ejection. 
- Reducing drilling forces: An arc cutting edge in the middle of the cutting lip may increase the rake angle with a reduced chisel edge length to decrease the thrust force.

- Improving drill centering: The outer cutting edges of MFD must be short enough so that the tips of the outer cutting edges can touch the surface of the workpiece for centering.

\section{Conclusions}

In this paper, the drilling characteristics of hybrid CFRP/Ti stacks have been experimentally studied. The effectiveness of different cutting sequence strategies and different tool geometries/ materials in drilling CFRP/Ti stacks has been systematically investigated, and their results are compared. The experimental work has highlighted the vital roles of cutting sequence strategies and tool geometries/materials in affecting the final CFRP/Ti drilling responses. Based on the results acquired, the following specific conclusions can be drawn.

- Drilling hybrid CFRP/Ti stacks in either CFRP $\rightarrow$ Ti sequence or $\mathrm{Ti} \rightarrow$ CFRP sequence basically involves five cutting stages with respect to the characteristics of tool-work interaction. The most challenging cutting stage is usually the interface drilling due to the existence of the multi-tool-work interaction, in which coupled chip separation modes and severe transitions of mechanical/physical responses predominate. Besides, the conventionally used concepts for standard CFRP machining and single Ti alloy machining are inappropriate for stacked CFRP/Ti interface drilling. This will lead the manufacturing community to develop a new concept of the machinability of the interface zone. In interface drilling, a particular attention should be paid to the careful control of the coupling effects in chip separation, the instability of the tool-work interaction, as well as the tool wear and cutting-induced damage.

- The machinability classification of CFRP/Ti drilling can be made according to the on-site features of tool-work interactions governing the chip removal process. For CFRP $\rightarrow \mathrm{Ti}$ cutting sequence, the cutting durations of $t \in\left[0, t_{2}\right]$ (stage $a-c$ ), $t \in$ $\left[t_{2}, t_{3}\right]$ (stage $c-d$ ), and $t \in\left[t_{3}, t_{5}\right]$ (stage $d-f$ ) usually signify the machinability of pure CFRP phase drilling, stacked CFRP/Ti interface drilling and pure Ti phase drilling, respectively.

- The force analysis shows that the uncoated drill A promotes lower drilling forces than the TiAlN-coated drill B under the same cutting sequence and cutting parameters because of its small chisel edge length and low point angle. The findings probably indicate that the tool geometrical features (e.g., chisel edge length, point angle and helix angle) exhibit more significant effects on drilling forces than tool material composition when drilling hybrid CFRP/Ti stacks. In addition, both cutting speed and feed rate are found to have a significantly positive impact on the force magnitudes, regardless of the used drill bits or cutting sequences.

- When drilling hybrid CFRP/Ti stacks, both long to short "ribbon" and "spiral" Ti chip types are produced with respect to different drill bits and cutting parameters. High feed rate usually results in the short segmented $\mathrm{Ti}$ chips and thus facilitates the improvement of chip breakability. By contrast, the effect of cutting speed on resected Ti chip type is insignificant.

- Hole quality including machined surface roughness and hole size accuracy is found to be greatly affected by the implemented drilling sequences and cutting parameters. For surface roughness inspection, the feed rate is a key factor that greatly influences the drilled hole surface finish, while the impact of cutting speed is obscure and insignificant. Moreover, for all tested trials, the arithmetic mean roughness $\left(R_{a}\right)$ values of drilled Ti phase holes are found to be totally controlled below the criterion value of $R_{a}=1.6 \mu \mathrm{m}$, whereas for machined CFRP holes, the $R_{a}$ values are partly achieved below the criterion value of $R_{a}=3.2 \mu \mathrm{m}$ greatly dependent on the used cutting parameters. For hole diameter and roundness error, both cutting speed and feed rate have pronounced effects on the measured values. The $\mathrm{Ti} \rightarrow \mathrm{CFRP}$ cutting sequence is found to generate lower surface roughness values and more consistent $\mathrm{CFRP} / \mathrm{Ti}$ hole diameters in contrast with the CFRP $\rightarrow$ Ti drilling due to the avoided severe abrasions on the drilled CFRP holes from Ti chip evacuation.

- Hole damage analysis shows that the CFRP $\rightarrow$ Ti drilling promotes a lower delamination extent than $\mathrm{Ti} \rightarrow$ CFRP drilling under the identical cutting conditions owing to the supporting role of bottom Ti alloy in increasing the stiffness of the exit CFRP hole layer. Besides, the feed rate is confirmed to play a vital role in affecting the drilling-induced delamination formation. Furthermore, from the aspect of minimizing the burr defects, the $\mathrm{Ti} \rightarrow$ CFRP drilling commonly produces a lower defect extent when high feed rates are applied as compared to the CFRP $\rightarrow$ Ti drilling.

- In general, the uncoated drill A yields a better tool performance than the TiAlN-coated drill $\mathrm{B}$ in terms of various drilling responses (e.g., force generation, induced hole damage extent) when performed under the identical cutting conditions. The findings probably suggest that when drilling hybrid CFRP/Ti stacks, the selection of optimal geometrical features should be a more effective method to improve the machinability of the bi-material system than the choice of superior tool materials. The TiAlN coating has very negligible influences on the drilled hole quality mainly due to the occurrence of severe chipping failure or coating peeling even after drilling quite a few number of CFRP/Ti holes [12], which makes the drill edges lose effective coating protection for producing high hole quality.

- Drill geometrical features including chisel edge length, point angle, and helix angle are confirmed to play a more vital role in affecting CFRP/Ti drilling responses than tool material composition. The chisel edge length in a drill bit accounts for the area of extrusion deformation action (aka "negative rake angle cutting") in chip separation and contributes mainly to the drilling forces. For point angle and helix angle, they often determine the drill main cutting edge length, tool edge sharpness and the proportion of thrust force in the nominal force generation in drilling. As such, drill B in present research cases with longer chisel edge length, larger point angle and helix angle is found to promote higher thrust force magnitudes and larger extents of delamination damage as compared to drill $\mathrm{A}$.

- The key mechanisms governing the influences of different cutting sequence strategies on CFRP/Ti drilling responses primarily depend on which stacked phase acts as a supporting role in increasing the stiffness of the exit top phase for minimizing the exit damage extent and also the absence/existence of the problematic Ti chip evacuation on the brittle CFRP hole wall surfaces. According to the present studies, the key effects of different cutting sequence strategies on various CFRP/Ti drilling responses can be summarized in Table 6 , in which the symbol " $\uparrow$ " indicates the improvement or acceleration, " $\downarrow$ " signifies the deterioration or reduction, and "--" denotes the insignificant or minor effects. Through the acquired results, it can be concluded that both two cutting sequences have a significant effect on the final CFRP/Ti drilling responses. For Ti $\rightarrow$ CFRP drilling, the strategy is found to benefit the improvement of the drilled CFRP hole quality (e.g., producing more consistent hole diameters and much better surface finish) and favor the decreased Ti burr extents, while the CFRP $\rightarrow$ Ti drilling facilitates only the reduced delamination extents throughout the experimental studies. In general, the $\mathrm{Ti} \rightarrow$ CFRP configuration 
Table 6

Comparative influences of two different cutting sequence strategies on CFRP/Ti drilling responses.

\begin{tabular}{|c|c|c|c|c|c|c|}
\hline \multirow[t]{2}{*}{ Drilling sequence } & \multirow[t]{2}{*}{ Drilling forces } & \multirow[t]{2}{*}{ Chip type } & \multicolumn{2}{|l|}{ Hole quality } & \multicolumn{2}{|l|}{ Hole damage } \\
\hline & & & Surface roughness & Hole diameter & Delamination & Burr width \\
\hline $\mathrm{CFRP} \rightarrow \mathrm{Ti}$ & $\uparrow$ & - & $\uparrow$ & $\uparrow$ & $\downarrow$ & $\uparrow$ \\
\hline $\mathrm{Ti} \rightarrow \mathrm{CFRP}$ & $\downarrow$ & - & $\downarrow$ & $\downarrow$ & $\uparrow$ & $\downarrow$ \\
\hline
\end{tabular}

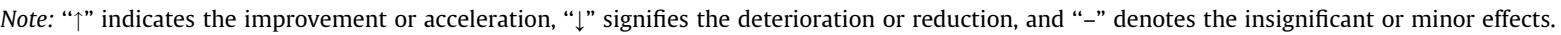

seems to be a more reasonable strategy for one-shot drilling of hybrid CFRP/Ti stacks especially under the utilized cutting conditions in the present work. However, this drilling strategy will inevitably give rise to an increased exit CFRP delamination extent. And this will lead the machinists to develop a particular process for CFRP/Ti drilling such as adding a supporting plate beneath the bottom CFRP phase in order to avoid the induced exit delamination damage.

- Finally, through the experimental results and theoretical analyses, a suggested functional design of MFD for drilling CFRP/Ti stacks is discussed and offered. In the future, the use of specialized drill bits will become an increasing trend in the industrial sectors in order to effectively improve the machinability of the multi-phase materials.

\section{Acknowledgements}

The authors gratefully acknowledge the financial support of China Scholarship Council (CSC) (Contract No. 201306230091). The authors also would like to thank Mr. Julien Voisin for his technical assistance throughout the drilling experiments.

\section{References}

[1] Xu J, Mkaddem A, El Mansori M. Recent advances in drilling hybrid FRP/Ti composite: a state-of-the-art review. Compos Struct 2016;135:316-38.

[2] Ezugwu EO, Wang ZM. Titanium alloys and their machinability - a review. J Mater Process Technol 1997;68(3):262-74.

[3] Nurul Amin AKM, Ismail AF, Nor Khairusshima MK. Effectiveness of uncoated WC-Co and PCD inserts in end milling of titanium alloy-Ti-6Al-4V. J Mater Process Technol 2007;192:147-58.

[4] Liu Z, An Q, Xu J, Chen M, Han S. Wear performance of (nc-AlTiN)/(a-Si $\mathrm{N}_{4}$ ) coating and (nc-AlCrN)/(a-Si $\left.{ }_{3} \mathrm{~N}_{4}\right)$ coating in high-speed machining of titanium alloys under dry and minimum quantity lubrication (MQL) conditions. Wear 2013;305(1-2):249-59.

[5] Che D, Saxena I, Han P, Guo P, Ehmann KF. Machining of carbon fiber reinforced plastics/polymers: a literature review. J Manuf Sci Eng-Trans ASME 2014;136 (3):034001.

[6] Liu D, Tang Y, Cong WL. A review of mechanical drilling for composite laminates. Compos Struct 2012:94(4):1265-79.

[7] Sinmazçelik T, Avcu E, Bora MÖ, Çoban O. A review: fibre metal laminates, background, bonding types and applied test methods. Mater Des 2011;32 (7):3671-85.

[8] Pawar OA, Gaikhe YS, Tewari A, Sundaram R, Joshi SS. Analysis of hole quality in drilling GLARE fiber metal laminates. Compos Struct 2015;123:350-65.

[9] Ramulu M, Branson T, Kim D. A study on the drilling of composite and titanium stacks. Compos Struct 2001;54(1):67-77.

[10] Park KH, Beal A, Kim D, Kwon P, Lantrip J. Tool wear in drilling of composite/ titanium stacks using carbide and polycrystalline diamond tools. Wear 2011:271(11-12):2826-35.

[11] Kim D, Ramulu M. Drilling process optimization for graphite/bismaleimidetitanium alloy stacks. Compos Struct 2004;63(1):101-14.

[12] Isbilir O, Ghassemieh E. Comparative study of tool life and hole quality in drilling of CFRP/titanium stack using coated carbide drill. Mach Sci Technol 2013;17(3):380-409.

[13] Qi Z, Zhang K, Li Y, Liu S, Cheng H. Critical thrust force predicting modeling for delamination-free drilling of metal-FRP stacks. Compos Struct 2014;107: 604-9.
[14] Tashiro T, Fujiwara J, Inada K. Drilling of CFRP/Ti-6Al-4V stacks. Adv Mater Res 2011;325:369-74.

[15] Park KH, Kwon P, Kim D. Wear characteristic on BAM coated carbide tool in drilling of composite/titanium stack. Int J Precis Eng Manuf 2012;13 (7):1073-6.

[16] Ghassemieh E. Performance and wear of coated carbide drill in machining of carbon fibre reinforced composite/titanium stack. Int J Mater Prod Technol 2012;43(1-4):165-83.

[17] Wang X, Kwon PY, Sturtevant C, Kim D, Lantrip J. Comparative tool wear study based on drilling experiments on CFRp/Ti stack and its individual layers. Wear 2014;317(1-2):265-76.

18] Brinksmeier E, Janssen R. Drilling of multi-layer composite materials consisting of carbon fiber reinforced plastics (CFRP), titanium and aluminum alloys. CIRP Ann - Manuf Technol 2002;51(1):87-90.

[19] SenthilKumar M, Prabukarthi A, Krishnaraj V. Study on tool wear and chip formation during drilling carbon fiber reinforced polymer (CFRP)/titanium alloy (Ti6Al4V) stacks. Procedia Eng 2013;64:582-92.

[20] Fujiwara J, Nagaura R, Kuroda K, Tashiro T. Drilling of CFRP/Ti6Al4V stack board. In: Proc 16th international conference on mechatronics technology. Tianjin, China, 16-19 October. p. 285-9.

[21] Shyha IS, Soo SL, Aspinwall DK, Bradley S, Perry R, Harden P, et al. Hole quality assessment following drilling of metallic-composite stacks. Int J Mach Tools Manuf 2011:51(7-8):569-78.

[22] Shyha I, Aspinwall D, Soo SL, Bradley S. Drill geometry and operating effects when cutting small diameter holes in CFRP. Int J Mach Tools Manuf 2009;49 (12):1008-14.

[23] Sharif S, Rahim EA. Performance of coated- and uncoated-carbide tools when drilling titanium alloy-Ti-6Al4V. J Mater Process Technol 2007;185(1-3):72-6.

[24] Xu J, El Mansori M. Cutting modeling using cohesive zone concept of titanium/ CFRP composite stacks. Int J Precis Eng Manuf 2015;16(10):2091-100.

[25] Xu J, El Mansori M. Numerical modeling of stacked composite CFRP/Ti machining under different cutting sequence strategies. Int J Precis Eng Manuf 2016;17(1):99-107.

[26] Kim D, Ramulu M. Study on the drilling of titanium/graphite hybrid composites. J Eng Mater Technol - Trans ASME 2007;129(3):390-6.

[27] Kim D, Sturtevant C, Ramulu M. Usage of PCD tool in drilling of titanium/graphite hybrid composite laminate. Int J Mach Mach Mater $2013 ; 13(2-3): 276-88$

[28] Chen WC. Some experimental investigations in the drilling of carbon fiberreinforced plastic (CFRP) composite laminates. Int J Mach Tools Manuf 1997;37(8):1097-108.

[29] Davim JP, Reis P. Drilling carbon fiber reinforced plastics manufactured by autoclave-experimental and statistical study. Mater Des 2003;24(5):315-24.

[30] Tsao CC, Hocheng H. Taguchi analysis of delamination associated with various drill bits in drilling of composite material. Int J Mach Tools Manuf 2004;44 (10):1085-90.

[31] Hocheng H, Tsao CC. The path towards delamination-free drilling of composite materials. J Mater ProcessTechnol 2005;167(2-3):251-64.

[32] Tsao CC, Hocheng H. Effect of tool wear on delamination in drilling composite materials. Int J Mech Sci 2007;49(8):983-8.

[33] Garrick R. Drilling advanced aircraft structures with PCD (poly-crystalline diamond) drills. In: AeroTech congress \& exhibition. Los Angeles, CA, USA, 18 20 September. p. 1-9.

[34] Kuo CL, Soo SL, Aspinwall DK, Bradley S, Thomas W, M'Saoubi R, et al. Too wear and hole quality when single-shot drilling of metallic-composite stacks with diamond-coated tools. Proc Inst Mech Eng Pt B-J Eng Manuf 2014;228 (10):1314-22

[35] Zitoune R, El Mansori M, Krishnaraj V. Tribo-functional design of double cone drill implications in tool wear during drilling of copper mesh/CFRP/woven ply Wear 2013;302(1-2):1560-7.

[36] Zitoune R, Krishnaraj V, Collombet F, Le Roux S. Experimental and numerica analysis on drilling of carbon fibre reinforced plastic and aluminium stacks. Compos Struct 2016;146:148-58. 